\title{
Structure and dynamics of the sudden acceleration of Kuroshio off Cape Shionomisaki
}

\author{
Toru Miyama • Yasumasa Miyazawa
}

Received: 1 August 2012 / Accepted: 2 January 2013 / Published online: 17 January 2013

(C) The Author(s) 2013. This article is published with open access at Springerlink.com

\begin{abstract}
A sudden acceleration of the Kuroshio jet appears off Cape Shionomisaki in the high-resolution (horizontal resolution of $1 / 36^{\circ}$ ) JCOPE 2 ocean reanalysis data. Using this dataset, we investigated the structure of the Kuroshio acceleration. The increase in the velocity of the current is accompanied by a downstream flow separation from the coast and an outcrop of cold temperature inshore. The acceleration of Kuroshio appears when it takes a nearshore path. Cape Shionomisaki amplifies the responses to the Kuroshio flow by creating the zonal velocity acceleration toward the downstream region when the Kuroshio flows closer to the coast. The Kuroshio acceleration coincided with the topographic ridge on the continental shelf near Cape Shionomisaki. This relation suggests that the dynamics of the acceleration is linked to the topographic feature. We proposed an explanation of the Kuroshio acceleration using a hydraulic control theory. An analytical solution was applied to the coastal topography around the Kii Peninsula. The solution captured some aspects of the Kuroshio acceleration.
\end{abstract}

Keywords Kuroshio $\cdot$ Jet $\cdot$ Hydraulic control $\cdot$ Coastal current $\cdot$ Assimilation data $\cdot$ Front genesis

Responsible Editor: Leo Oey

This article is part of the Topical Collection on the 4th International Workshop on Modelling the Ocean in Yokohama, Japan 21-24 May 2012

T. Miyama $(\bowtie) \cdot$ Y. Miyazawa

Research Institute for Global Change, Japan Agency

for Marine-Earth Science and Technology,

3173-25 Showamachi, Kanazawa-ku,

Yokohama 236-0001, Japan

e-mail: tmiyama@jamstec.go.jp

\section{Introduction}

Observational studies (Konaga et al. 1967, 1971; Minami 1977; Shuto 1979) have reported sudden accelerations of the Kuroshio jet in the surface current off Cape Shionomisaki on the southernmost tip of the Kii Peninsula (Fig. 1). The studies also found discontinuous changes of water properties between the Kii Channel and the Kumano-Nada region (from the west to the east sea of the Kii Peninsula) accompanying these sudden velocity increase. The acceleration of the Kuroshio velocity typically appeared when the current took near-shore paths (Kawabe 1990). Using an analytic solution, Kawabe (1990) concluded that the velocity increase off Cape Shionomisaki is necessary for shaping realistic non-large-meander paths of the Kuroshio.

In this study, we show that the velocity accelerations of the Kuroshio are also visible in an ocean-reanalysis dataset. Because the observations of the Kuroshio acceleration were limited in space and time, the reanalysis data is useful to describe the detailed structure of the Kuroshio acceleration. One of the objectives of this study is to describe the sudden acceleration of Kuroshio using the ocean reanalysis data.

Another objective is to find a possible explanation of what causes this acceleration. To the best of our knowledge, no adequate dynamical explanation of the flow acceleration has been proposed.

Minami (1977) suggested that the Kuroshio acceleration is the result of the penetration of the coastal water and consequent horizontal convergence of the water into the Kuroshio. However, he did not explain why the convergence occurs. It is possible that the flow convergence might be the result of the Kuroshio acceleration, and not the cause.

Shuto (1979) found that the flow acceleration started above an underwater ridge near Cape Shionomisaki and that the Kuroshio meandered slightly as it passed over 


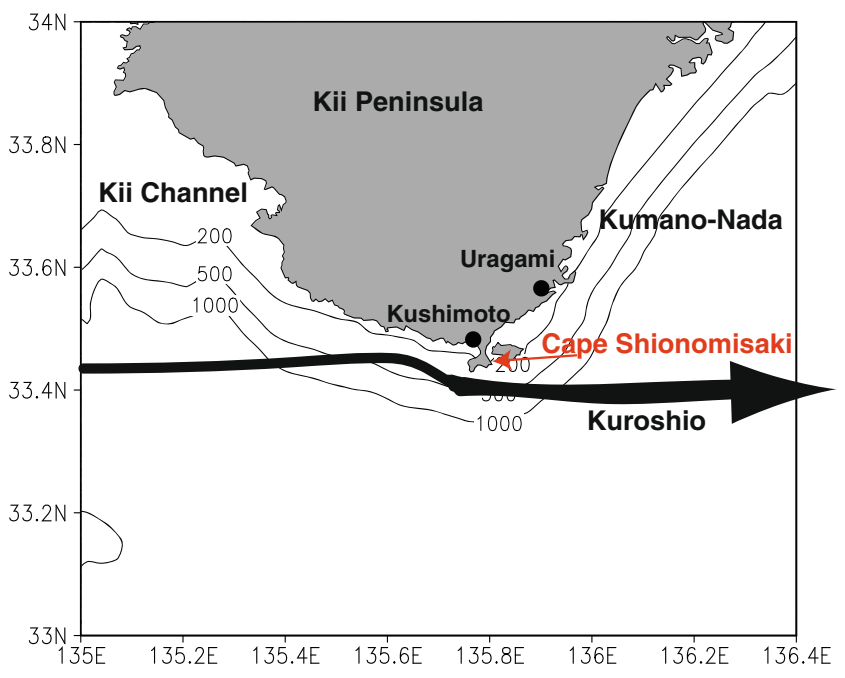

Fig. 1 Map of the vicinity of Cape Shionomisaki. The cape is the southern tip of the Kii Peninsula in the southern coast of Honshu Island, Japan. Contour lines show bottom topography (meters). The Kuroshio flow is schematically illustrated. See Fig. 2 for a larger map

this ridge. Based on these observations, Shuto (1979) discussed linear theories of slope current affected by bottom topography. These theories might explain the slight meander of the Kuroshio off Cape Shionomisaki, but not its acceleration. Because the flow is very rapid after the acceleration (nearly $2 \mathrm{~m} / \mathrm{s}$ according to his observation), we think that a nonlinear effect should be considered.

In terms of nonlinearity, Nagata et al. (1999) studied the centrifugal force along the bottom slope near Cape Shionomisaki. However, their focus was on the flow separation of the Kuroshio from the coast to the east of Cape Shionomisaki, and not its acceleration. Moreover, Konaga et al. (1967) did not find any significant flow curvature in the flow off Cape Shionomisaki in their observation of the Kuroshio acceleration.

In this study, we propose a dynamical explanation based on a hydraulic control theory. The hydraulic control theory describes the evolution along streamlines of a steady flow as it encounters gradual changes in the topography (Pratt and Whitehead 2007). A typical structure of a hydraulic solution is the transition from a slow (subcritical) flow to a rapid (supercritical) flow when passing a topographic anomaly. We believe this feature can explain the acceleration of the Kuroshio off Cape Shionomisaki.

This paper is organized as follows. In Section 2, we present the data used in our analysis - the JCOPE2 reanalysis dataset. In Section 3, we describe the features of the Kuroshio acceleration in the reanalysis data. In Section 4, we propose a possible explanation of the flow acceleration using the hydraulic theory. In Section 5, we summarize and discuss the results.

\section{Model data}

The reanalysis data used in this study is a product of the Japan Coastal Ocean Predictability Experiment 2 (JCOPE2) (Miyazawa et al. 2009). The dataset used in this study has higher resolution (horizontal grid of $1 / 36^{\circ}$ and 46 vertical levels) than the standard JCOPE2 product (horizontal grid of $1 / 12^{\circ}$ and 46 vertical levels). The data covers the $28-36^{\circ}$ $\mathrm{N}, 128-142^{\circ} \mathrm{E}$ (Fig. 2). The lateral boundary conditions were determined from the standard JCOPE2 reanalysis using a one-way nesting method with a flow relaxation scheme (Oey and Chen 1992; Guo et al. 2003). Refer to Miyazawa et al. (2009) for details of the JCOPE2 reanalysis, or visit http://www.jamstec.go.jp/frcgc/jcope/. We used the daily mean data from August 2003 to December 2007 because this is the longest period for which continuous data was available without any gaps at the point of this study.

For a quick check of the validity of the JCOPE2 data, two indices of the Kuroshio variation around the Kii Peninsula were compared with observations. The first comparison is of the monthly time series of the southernmost latitude of the Kuroshio path between $136^{\circ} \mathrm{E}$ and $140^{\circ} \mathrm{E}$ (Fig. 3a). The latitude of Kuroshio in the JCOPE2 is defined from the location of maximum velocity between $136^{\circ} \mathrm{E}$ and $140^{\circ} \mathrm{E}$, $30.5-35^{\circ} \mathrm{E}$ at $10-\mathrm{m}$ depth. The Kuroshio latitude of the JCOPE2 (the solid line) is in good agreement with the latitude variation taken from the observations (dashed line) provided by the Japan Meteorological Association (JMA, available from http://www.data.kishou.go.jp/kaiyou/shindan/b_2/ kuroshio_stream/kuroshio_stream.html). The correlation between these lines is high, 0.94 , with a $99 \%$ confidence level (hereafter all correlations mentioned in this study are significant with a $99 \%$ confidence level). Note that this data includes

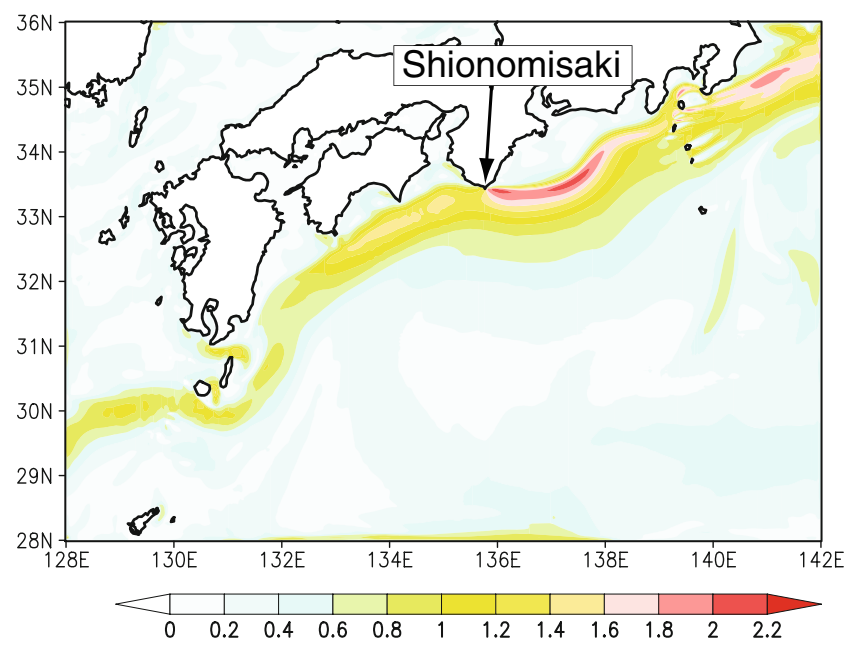

Fig. 2 The whole domain of the JCOPE2 data used in this study. Color shading shows the absolute velocity (meters per second) at surface (at $10 \mathrm{~m}$ depth) when a typical Kuroshio acceleration appeared on August 9, 2003 
Fig. 3 Time series of the monthly mean values of the Kuroshio indices. The solid lines were calculated from the JCOPE2 data. The dashed lines were obtained from the Japan Meteorological Agency (JMA). a The southernmost latitudes (degree) of the Kuroshio path between $136^{\circ} \mathrm{N}$ and $140^{\circ} \mathrm{N}$. b The sea level differences (meters) between Kushimoto and Uragami
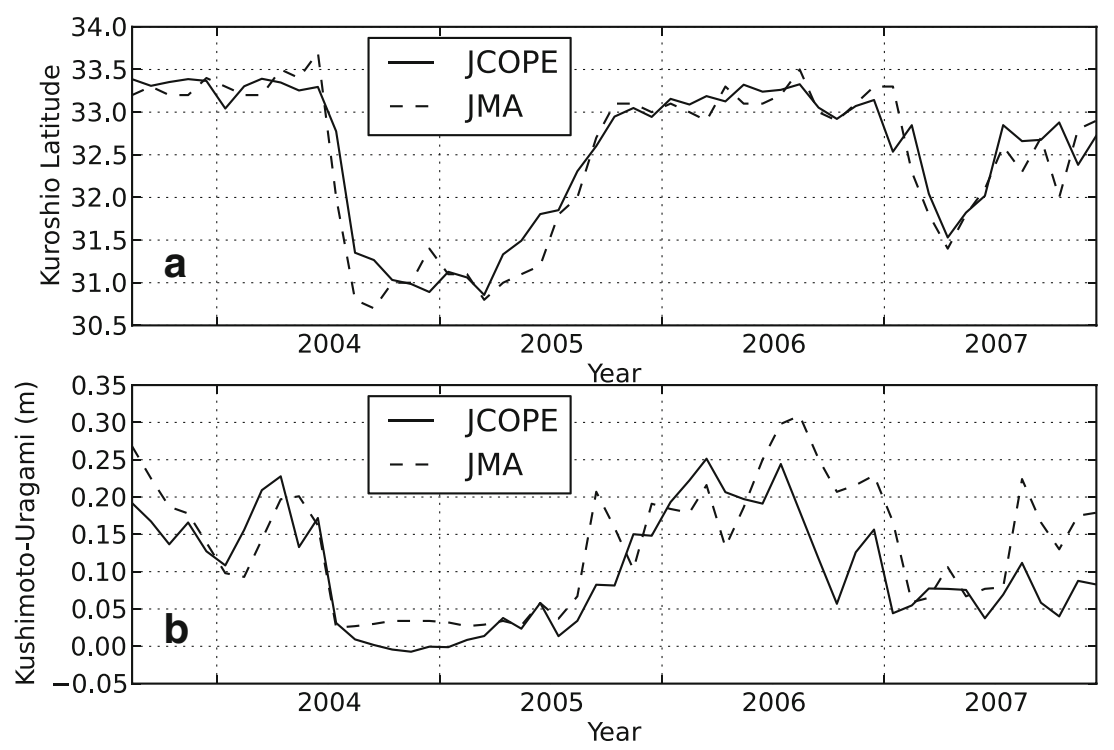

a Kuroshio large meander period, which manifests as a southward shift of the Kuroshio path, from the second half of 2004 to the first half of 2005 (Miyazawa et al. 2008).

The second comparison (Fig. 3b) is of the sea level difference between Kushimoto and Uragami (for locations, see Fig. 1). This sea level difference between Kushimoto and Uragami is well known as a good index of the Kuroshio path, e.g., Sekine and Fujita (1999). This aspect is discussed in the next section. The correlation of the monthly sea level difference between the JCOPE2 data (solid line) and observations (dashed line) provided by JMA (available also from the above URL) is 0.76 , not as high as Fig. 3a, but still satisfactory.

Figure 3 confirms that the JCOPE2 reanalysis data used in this study captures the variations of the Kuroshio in this region reasonably well. The lower correlation in Fig. 3b could be because of the effects of the complicated topography on the sea level along the coast, which makes it difficult to reproduce the variations of the sea levels with the $1 / 36^{\circ}$ resolution.

\section{Data analysis}

In Section 3.1, we describe a typical pattern of the Kuroshio acceleration from a snapshot in the JCOPE2 data. In Section 3.2, we show the temporal variation of the Kuroshio acceleration and the condition in which the acceleration tends to appear. Using statistical analyses, we further discuss the structure of the Kuroshio acceleration.

\subsection{Typical structure of the Kuroshio acceleration}

Figure 2 shows the velocity pattern at the surface (10-m depth) during a Kuroshio acceleration event in the JCOPE2 data on
August 9, 2003. At that time, the Kuroshio took a near-shore path. The Quick Bulletin of Ocean Conditions published by the Japan Coast Guard (http://wwwl.kaiho.mlit.go.jp/ KANKYO/KAIYO/qboc/2003/qboc200332cu0.pdf) confirms that the Kuroshio Current was in the near-shore path. From the tip of the Shionomisaki, a high velocity area emerged and stretched downstream.

A closer look at the surface velocity off Shionomisaki (Fig. 4) shows that the zonal velocity increased from $\sim 1 \mathrm{~m} / \mathrm{s}$ on the upstream side of Shionomisaki to $\sim 2 \mathrm{~m} / \mathrm{s}$ on the downstream. Although the model coastline of the current resolution (white blank in Fig. 4) is the simplified one from reality (Fig. 1), the velocity increase at the place of Cape Shionomisaki is abrupt. On the upstream side, the Kuroshio approached the west coast of the Kii Peninsula, and the flow

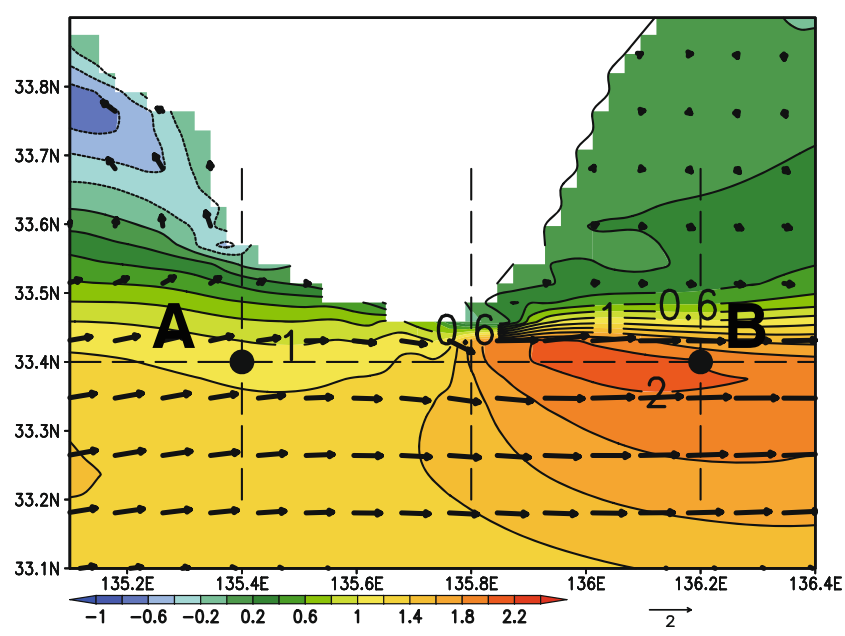

Fig. 4 Velocity (meters per second; vector) and the zonal velocity component of the velocity (meters per second; color shading and contour) at $10 \mathrm{~m}$ depth in the vicinity of Cape Shionomisaki. The dashed lines and points $A$ and $B$ are used in the following analyses. White blank shows the model land at this depth 
separated into northwestward and southeastward currents along the coast. This bifurcation is often seen in this region and is called the Kii Bifurcation Current (Furiwakeshio in Japanese; Takeuchi et al. 1998; Nagata et al. 1999; Uchida et al. 2000; Hukuda et al. 2002). The southeastward current continued into the accelerated flow downstream from the tip of Shionomisaki. The flow slightly shifted its direction southward and separated from the coast at Shionomisaki. This slight offshore shift was noted by Shuto (1979), and the separation from the coast was discussed by Nagata et al. (1999). The Kii Peninsula created a velocity shadow to the east, and the slow velocity in the Kumano-Nada region and the accelerated velocity of the Kuroshio formed a sharp gradient.

Figure 5 shows the water properties near the Kii Peninsula on August 9, 2003. The temperatures at $50 \mathrm{~m}$ (Fig. 5a) and $200 \mathrm{~m}$ (Fig. 5b) were lower in the Kumano-Nada region than in the Kii Channel. Consistent with the low temperatures, the sea level height (Fig. 5c) in the east of the Kii Peninsula was lower than in the west. Thus, as the Kuroshio flowed past Cape Shionomisaki, the temperature and the sea level to the east of the Kii Peninsula dropped, and the meridional pressure gradients across the Kuroshio intensified. The increase of the gradient is consistent with the velocity acceleration in a geostrophic sense. The shaper meridional gradient was also illustrated in the vertical sections of the temperature and zonal velocity fields in Fig. 6 along three meridional lines (north-south lines in Fig. 4). As the surface-trapped velocity of the Kuroshio increased from upstream to downstream (color shading in Fig. 6a-c), the isotherms (contour lines) in the inshore side rose toward the surface. As a result, the surface temperature to the east of the Kii Peninsula was colder than to the west. Similar isotherm structures were found in the observation by Nagata et al. (1999) (their Fig. 2). Sharp gradients of water properties on the downstream side were also found in other observations (Konaga et al. 1967, 1971; Minami 1977; Shuto 1979).

Shuto (1979) found in his observation that the surface current velocity of the Kuroshio was accelerated above the top of the continental slope ridge. In fact, the zonal velocity of the JCOPE2 data (Fig. 7) along the $33.4^{\circ} \mathrm{N}$ line (the dashed west-east line in Fig. 4) also shows that the velocity acceleration coincided with the topographic ridge. This topographic anomaly appears because the continental shelf curves toward the zonally flowing Kuroshio (the continental slope is plotted as contour lines in Fig. 1). The vertical section along the same line as Fig. 7 also shows the close relation of the acceleration to the topography (Fig. 8). As the Kuroshio passed over the continental shelf, the velocity (color shading in Fig. 8) concentrated toward the surface and increased above the ridge. The pycnocline $\sigma_{\theta}$ (blue contour in Fig. 8) also became sharper above the ridge toward the downstream region. The close relation of the
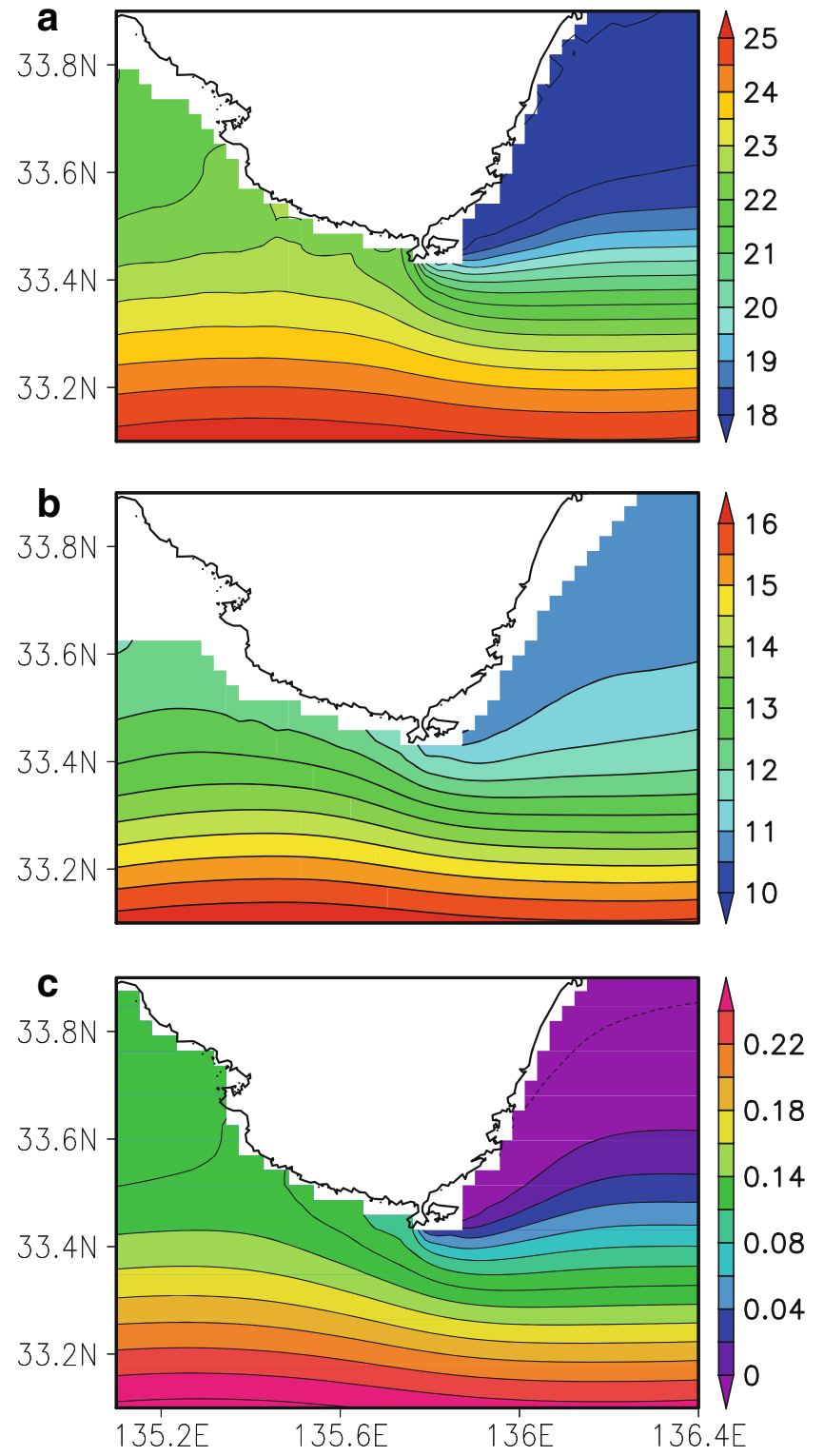

Fig. 5 Horizontal maps of the water properties around Cape Shionomisaki on August 9, 2003 from the JCOPE2 data. a Temperature (degrees Celsius) at $50 \mathrm{~m}$ depth. b Temperature (degrees Celsius) at $200 \mathrm{~m}$ depth. c Sea surface height (meters). White blank shows the model land at each depth

topography and acceleration suggests the importance of the topography in the Kuroshio flow dynamics and is discussed in Section 4.

\subsection{Statistical analysis}

To determine how often the Kuroshio acceleration appears, we plotted the longitude-time diagram of the daily surface zonal velocity along the $33.4^{\circ} \mathrm{N}$ line (Fig. 9) and found that the accelerations (sharp gradients) of the velocity are frequent events. At the longitude of Cape Shionomisaki (dotted 
Fig. 6 Meridional-vertical sections of the zonal velocity (meters per second; color shading) and the temperature (degrees Celsius; contour) along the three north-south dashed lines in Fig. 4: (a) $135.4^{\circ} \mathrm{E}$, (b) $135.8^{\circ} \mathrm{E}$, and (c) $136.2^{\circ}$ E. Black shade shows the model topography
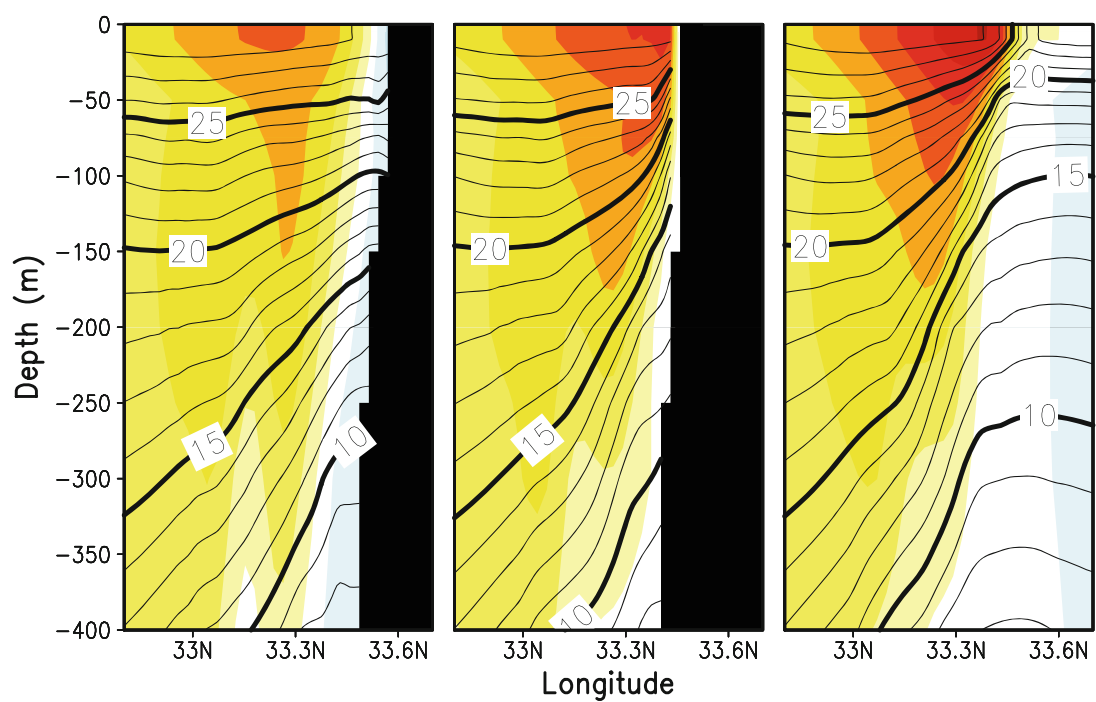

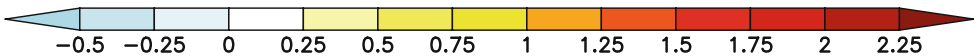

line in Fig. 9), the Kuroshio acceleration appeared often as a velocity gradient.

The Kuroshio acceleration was clearly absent from the latter half of 2004 to the first half of 2005. This period corresponds to the Kuroshio large meander period (Kagimoto et al. 2008; Miyazawa et al. 2008; Usui et al. 2008a, b). This indicates that the velocity jump is closely related with the path of the Kuroshio as mentioned by Kawabe (1990).

The variation of the Kuroshio acceleration and its relation to the Kuroshio path can be confirmed in Fig. 10. The black line is the daily time series of the zonal velocity difference from the point $135.4^{\circ} \mathrm{E}, 33.4^{\circ} \mathrm{N}$ to $136.2^{\circ} \mathrm{E}, 33.4^{\circ} \mathrm{N}$ (from point $\mathrm{A}$ to $\mathrm{B}$ in Fig. 4). Hereafter, the velocity difference between these points is called vdiff-BA, and the velocity at A (B) is called vel-A (vel-B). The red curve is the monthly averaged time series of vdiff-BA. While the daily value of vdiff-BA (black line) shows strong fluctuations, the monthly values shows that the velocity increase was around $1 \mathrm{~m} / \mathrm{s}$ from 2003 to the first half of 2004. The Kuroshio acceleration was absent from the second half of 2004 to the first half of 2005. The velocity again increased, reaching as high as $1 \mathrm{~m} / \mathrm{s}$ from the second half of 2005 to 2006 . The values of the velocity difference were weaker in 2007 than those in 2006.

The blue curve in Fig. 10 represents the latitude of the Kuroshio path from the JCOPE2 data shown in Fig. 3a. The comparison between the monthly velocity increase (vdiffBA, red curve) and the Kuroshio path (blue curve) shows that the velocity acceleration is highly correlated with the closeness of Kuroshio to the Japan coast. The correlation coefficient is 0.87 .

Although we would expect Kuroshio's location to directly influence current's velocity rather than the velocity difference, the correlation coefficient between the Kuroshio's latitude and the upstream velocity at location A (vel-A) is 0.71 (Fig. 11a), which is smaller than the correlation between the Kuroshio's latitude and vdiff-BA (0.87) in Fig. 10. Furthermore, the correlation using the monthly (daily) values between vel-A and vdiff-BA is $0.57(0.16)$, which is still significant but low (Fig. 11b). Conversely, the correlation coefficient between vdiff-BA and velocity at $\mathrm{B}$ (vel-B) on the downstream side is high 0.92 (0.83) using the monthly (daily) values (Fig. 11c).

The better relation of vdiff-BA to the velocity downstream than the upstream can be also confirmed by the horizontal distribution of the correlation of the surface velocity to vdiff-BA using the daily data (Fig. 12). The high

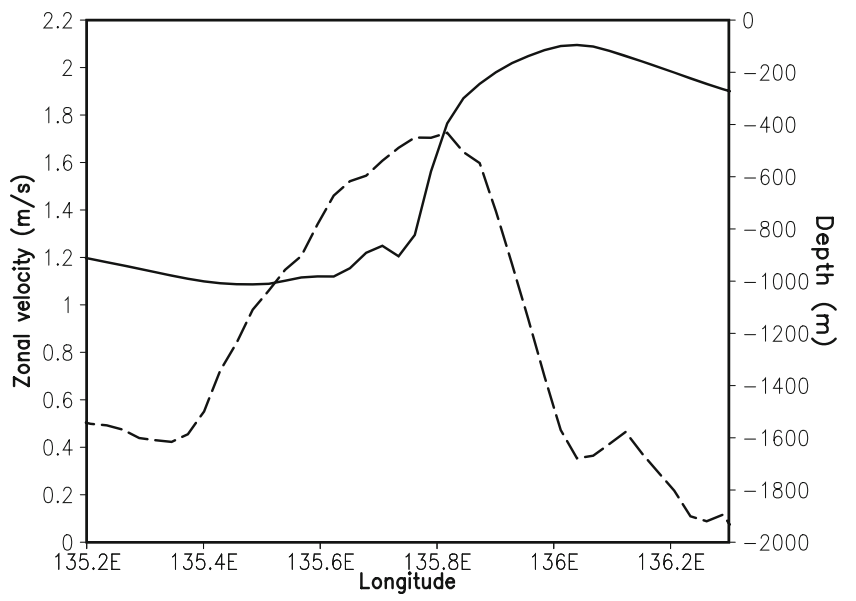

Fig. 7 Zonal velocity (solid line) at the surface and topography (dashed line) along the $33.4^{\circ} \mathrm{N}$ line (the dashed west-east line in Fig. 4) on August 9, 2003. The zonal velocity (meters per second) refers to the left-hand axis and, the bottom depth (meters) is indicated on the right-hand axis 


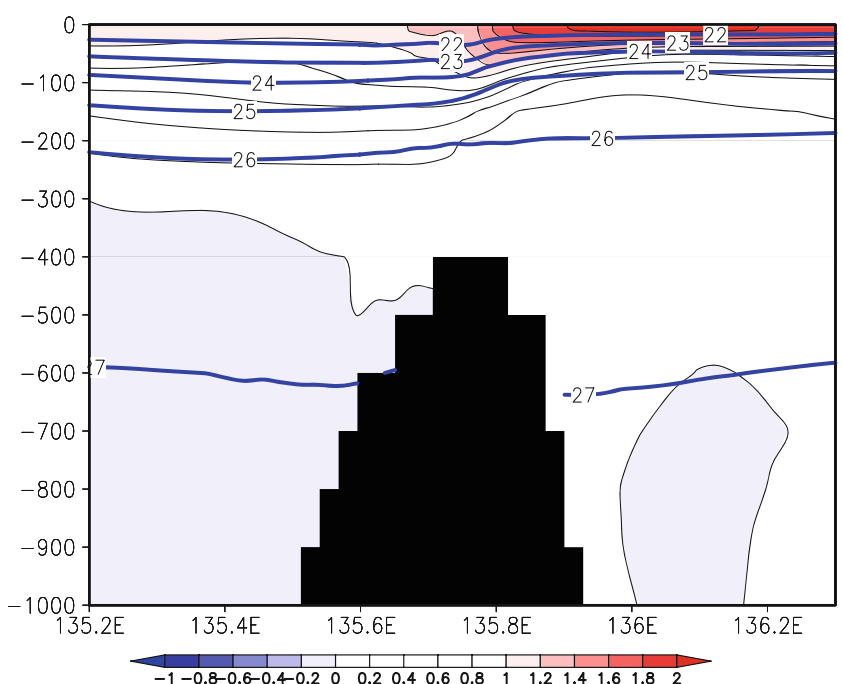

Fig. 8 Zonal-vertical section of the zonal velocity (meters per second; color shading and black contours) and the density ( $\sigma_{\theta} ;$ blue contours) along $33.4^{\circ} \mathrm{N}$ (the west-east line in Fig. 4) on August 9, 2003. Black shade shows the model topography

correlation stretched far eastward from the Kii Peninsula. This is consistent with Kawabe's (1990) idea that the Kuroshio acceleration has a profound effect on the downstream path of the Kuroshio. The correlation map using the monthly mean data shows a similar distribution to Fig. 12 with an even higher correlation (not shown).

The regression map of the sea level height and surface velocity to vdiff-BA (Fig. 13a) reveals the variations in the surrounding ocean accompanying the Kuroshio acceleration. As found in the correlation map (Fig. 12), the downstream zonal velocity increased with vdiff-BA. The order of the increase is $\sim 1 \mathrm{~m} / \mathrm{s}$ per unit increase of vdiff-BA $(1 \mathrm{~m} / \mathrm{s})$.

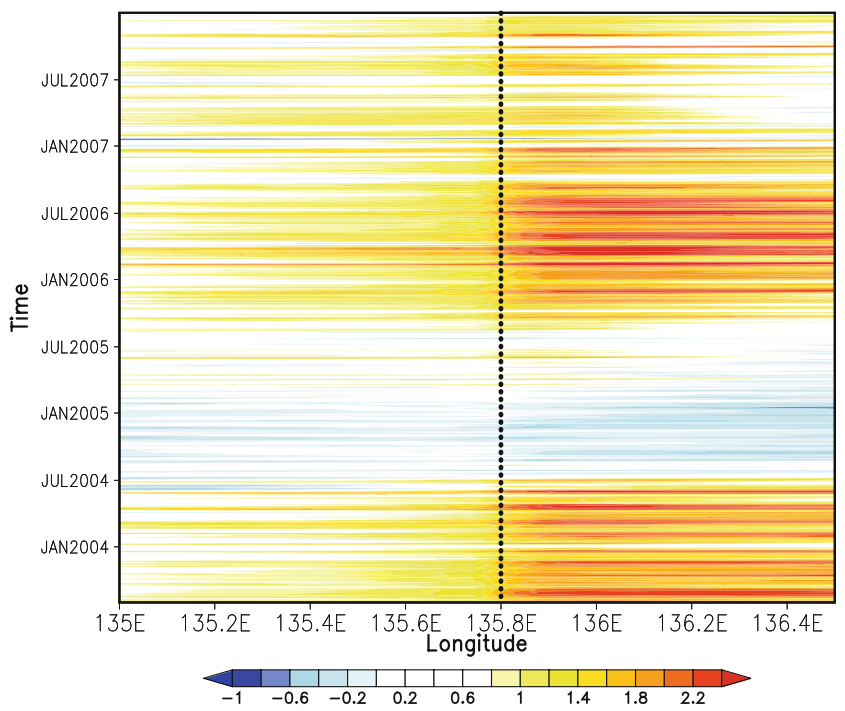

Fig. 9 The longitude-time diagram of the daily surface (at $10 \mathrm{~m}$ depth) zonal velocity along $33.4^{\circ} \mathrm{N}$ (the west-east line in Fig. 4). The dotted line denotes the longitude of Cape Shionomisaki $\left(135.8^{\circ} \mathrm{E}\right)$

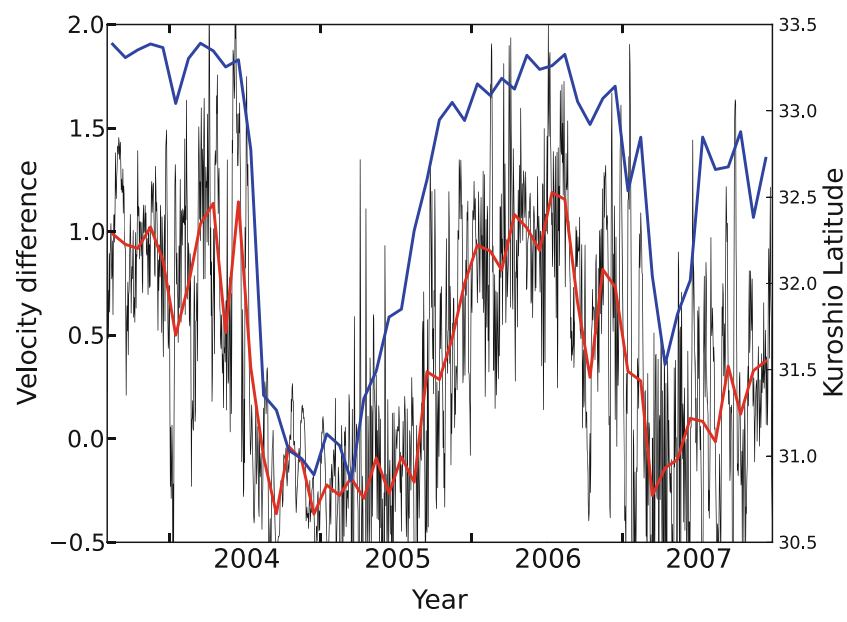

Fig. 10 The black line is the time series of the daily zonal velocity difference (at point B minus point A in Fig. 4; vdiff-BA; meters per second), and the red curve is its monthly mean time series (meters per second). The blue curve is the monthly mean time series of the southernmost latitude (degree) of the Kuroshio path between $136^{\circ} \mathrm{E}$ and $140^{\circ} \mathrm{E}$ from the JCOPE2 data (the same as the solid line in Fig. 3a)

Corresponding to the zonal velocity increase, the north-south gradient of the sea level was enhanced. The lower sea level in the Kumano-Nada region during a typical Kuroshio acceleration (Fig. 5) is statistically confirmed by Fig. 13a. Consistent with the sea level, the regression to temperature (not shown) shows that the temperature in Kumano-Nada drops during the Kuroshio acceleration. Using historical data, Sugimatsu and Isobe (2010) showed the water temperature of the east of the Kii peninsula was colder when the Kuroshio axes were located on the onshore side of $74 \mathrm{~km}$ than when located within the 74-km band. This is consistent with our analysis using the JCOPE data since the Kuroshio acceleration occurs when the Kuroshio's path is closer to the shore (Fig. 10). The large increase of the sea level offshore (south of $33.5^{\circ} \mathrm{N}$ ) on the downstream side corresponds to the absence of the Kuroshio large meander during the Kuroshio acceleration.

To check the robustness of the relation between the Kuroshio acceleration and the variations around it, another regression map (Fig. 13b) is shown only using the data from 2006, which does not include the Kuroshio large meander period. Responding to the fluctuations shown by the black line in Fig. 10, the features mentioned above are further confirmed: Kuroshio's velocity downstream increases, and the pressure gradient across the current is enhanced.

It has been long known that the sea level difference between the regions west and east of the Kii Peninsula increases when the Kuroshio takes the non-large-meander path (Kawabe 1989; Nagata et al. 1999; Sekine and Fujita 1999). The sea level difference between Kushimoto and Uragami (see Fig. 1 for locations) is often used as an index of the Kuroshio meander. Figure 13 shows that the sea level difference is a part of the large-scale enhancement of the pressure gradient across the increased zonal velocity in 

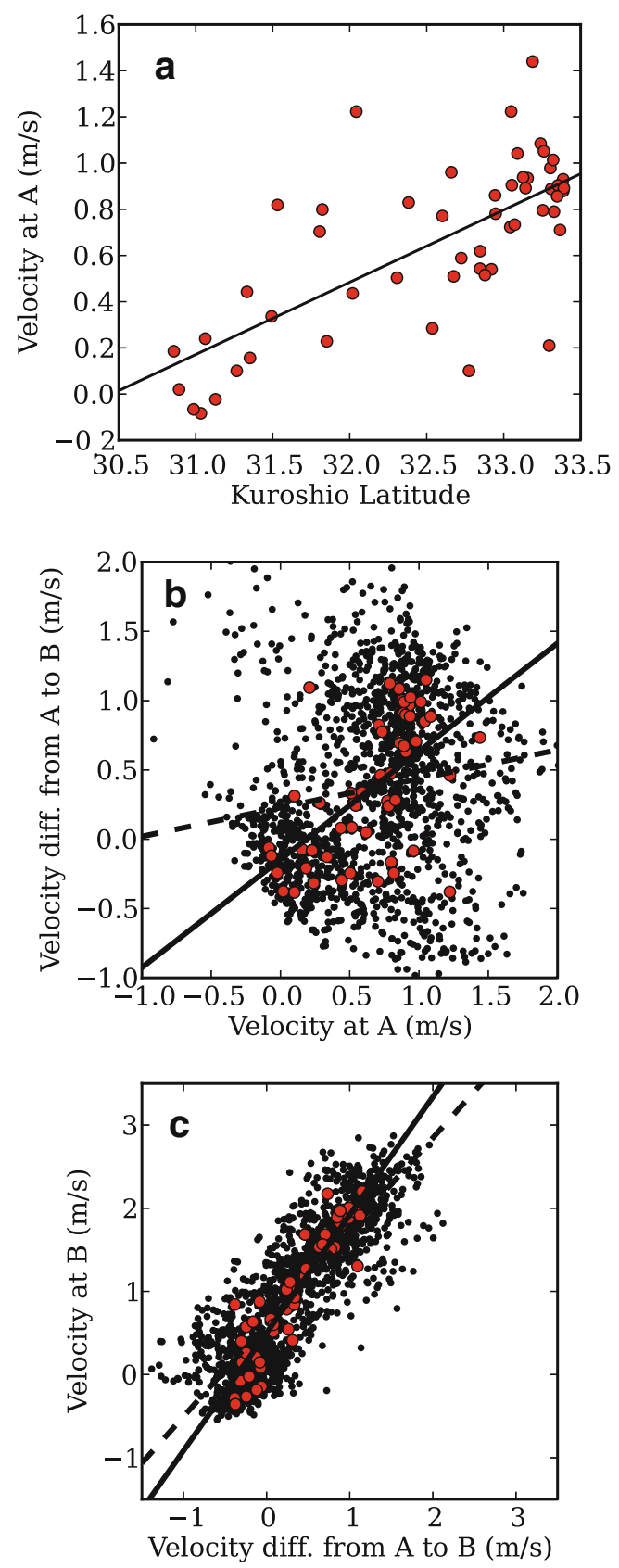

Fig. 11 Scatterplots comparing the Kuroshio latitude, the velocity difference, and the velocities. Red (black) dots indicate monthly (daily) values. The solid (dashed) lines are the linear regressions of the monthly (daily) data. a The latitude of the Kuroshio path and the velocity at A (vel-A). b The velocity at A (vdiff-A) and vdiff-BA. c vdiff-BA and the velocity at B (vel-B)

response to the Kuroshio acceleration. The results so far indicate that Cape Shionomisaki acts as an amplifier of the responses to the Kuroshio path by creating a zonal velocity acceleration when the Kuroshio takes a near-shore path.

The relation of the upstream velocity (vel-A) and the Kuroshio acceleration (vdiff-BA), which is not a clear linear relationship (Fig. 11b), is further analyzed. Figure 14 shows the two-dimensional probability distribution of the scatter of

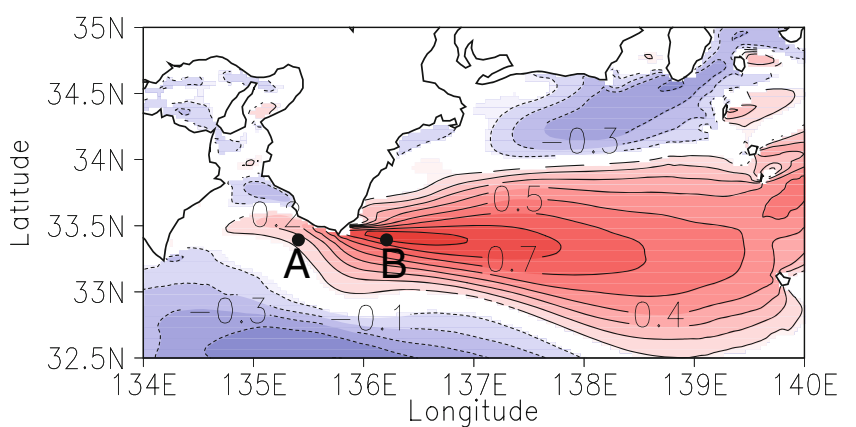

Fig. 12 Horizontal map of the correlation coefficient between the surface velocity (at $10 \mathrm{~m}$ depth) and the velocity increase from point $A$ to $B$ (vdiff-BA) using the daily data. The significant region with $99 \%$ confidence level is shaded. The dots near the Kii Peninsular indicate the locations of points $A$ and $B$ (Fig. 4)

vel-A and vdiff-BA. While most of the vdiff-BA values are near zero or negative when the vel-A values are small (velA $<$ $0.4 \mathrm{~m} / \mathrm{s}$ ), vdiff-BA jumps to the distributions of high values for large values of vel-A (velA $>0.4 \mathrm{~m} / \mathrm{s}$ ). This figure suggests that the upstream velocity and the Kuroshio acceleration have a nonlinear relationship, which is further discussed below.

\section{Dynamics}

The close relationship between the topographic ridge and acceleration of the Kuroshio flow mentioned in the previous

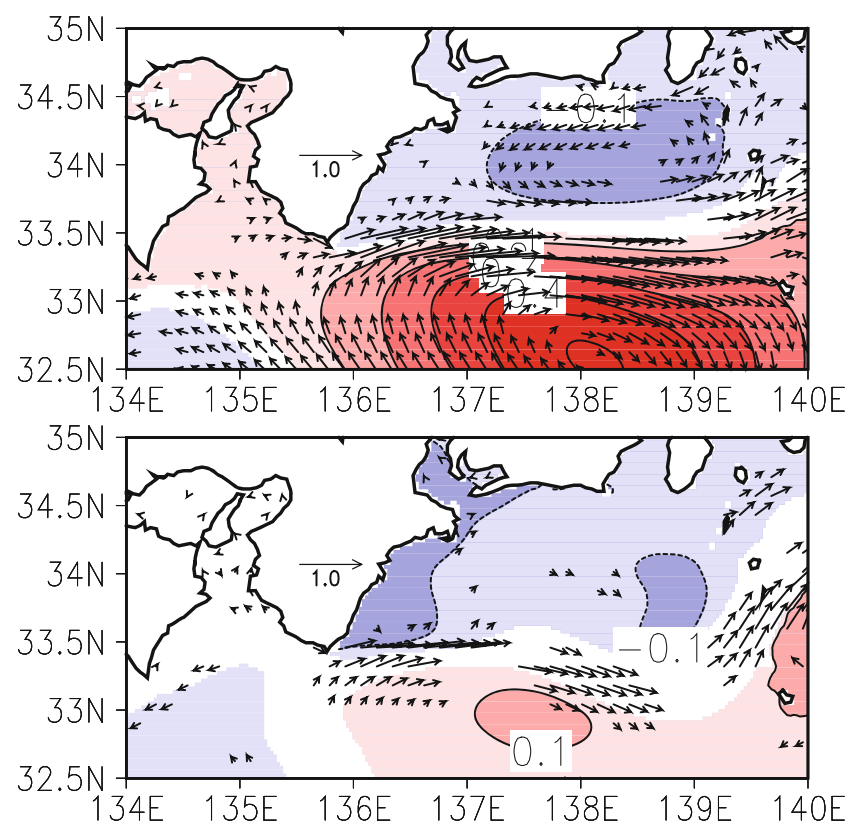

Fig. 13 Regression maps of the sea surface elevation (meters; color shading and contours) and the velocity (meters per second; vectors) at the surface $(10 \mathrm{~m}$ depth) to the zonal velocity difference vdiff-BA (meters per second). Only values with significance within the $99 \%$ confidence level are drawn. a Map using the whole time period. b Map using only 2006 data 


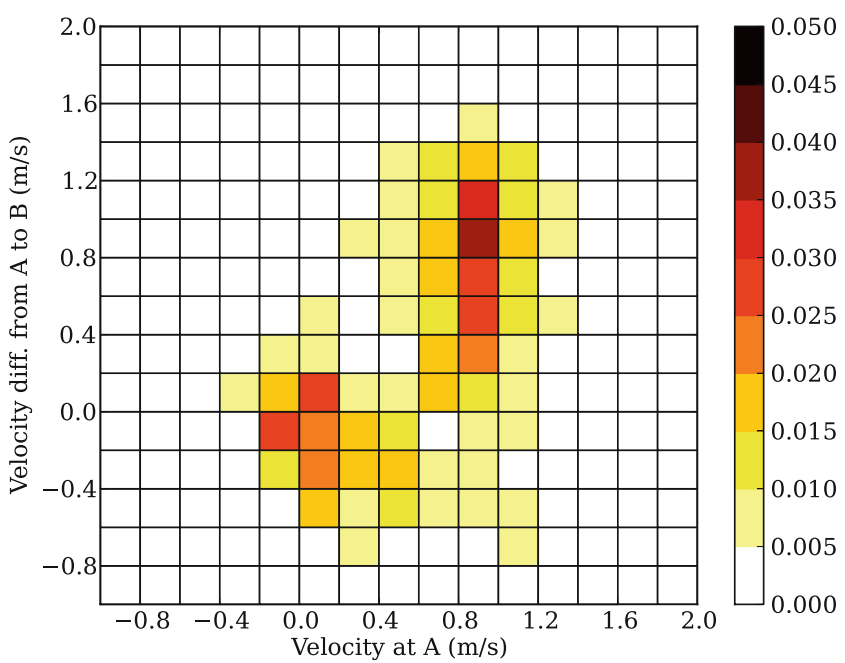

Fig. 14 Two-dimensional probability distribution calculated from the pairs of vel-A and vdiff-BA into bins with widths of $0.2 \mathrm{~m} / \mathrm{s}$

section led us to consider the hydraulic control theory. In Section 4.1, the hydraulic control theory is briefly introduced. Section 4.2 describes the formulations to derive the analytical solutions. Section 4.3 shows the results from the analytical solutions when applied to the Kuroshio acceleration.

\subsection{A brief introduction to hydraulic control theory}

The hydraulic theory describes the evolution of the flow from upstream to downstream over a topographic anomaly. There are many oceanographic applications of the hydraulic theory (refer to the textbook by Pratt and Whitehead (2007) for a comprehensive review). Of particular interest here is the coastal application. Previously, Gill and Schumann (1979) (for the Agulhas Current at Durban and Port Edward in the Southern Indian Ocean) and Dale and Barth (2001) (for the current around Cape Blanco in the Eastern Pacific Ocean) developed the hydraulic control theory for a coastal current encountering a cape-like topographic anomaly on a continental shelf. Their results are summarized in Chapter 4 of Pratt and Whitehead (2007). A prominent feature of their solutions is the smooth transition from a slow flow on the upstream side ("subcritical flow") to a jet ("supercritical flow") on the downstream side. The critical point at which the transition occurs is known as the "control point." At such a point, the current is exactly critical to a long coastal trapped wave, stalling its upstream propagation.

We applied a formulation based on Gill and Schumann (1979) and Dale and Barth (2001) for the Kuroshio around Cape Shionomisaki because of the similarity between the Kuroshio acceleration and their findings. Note that Shuto (1979) dismissed the possibility of applying hydraulics to the Kuroshio off Cape Shionomisaki. In his argument, he used an external wave speed in his scale analysis. However, we show here that the hydraulic theory is applicable to the Kuroshio acceleration by using an internal wave speed as follows.

\subsection{Formulations}

Following Gill and Schumann (1979) and Dale and Barth (2001), the model used here has 1.5 layers in the open ocean, but 2 layers on the continental shelf (Fig. 15). A coordinate system is set with the $x$-axis pointing seaward, and the $y$-axis parallel to the coast. The depth of layer $i$ is denoted $D_{i}$, and the horizontal velocities are $u_{i}$ and $v_{i}$ in the $x$ and $y$ directions, respectively. For $x>0$, the second layer is assumed to be so deep that the currents are effectively zero. The Boussinesq and hydrostatic approximations are made. The surface is capped by a rigid lid.

The shelf topography for $x<0$ is given with a linear slope $s=H / W$ of a continental shelf width $W$ and a depth $H$ at the continental edge. In our study, $W$ and $H$, and therefore $s$, all vary with $y$. Gill and Schumann (1979) considered the case with a constant $s$ along $y$, and Dale and Barth (2001) considered the case with a constant $H$ along $y$.

The width of the current is assumed to be small compared with the scale of the alongshore variations. It is also assumed that the alongshore scale of the cape is so long that
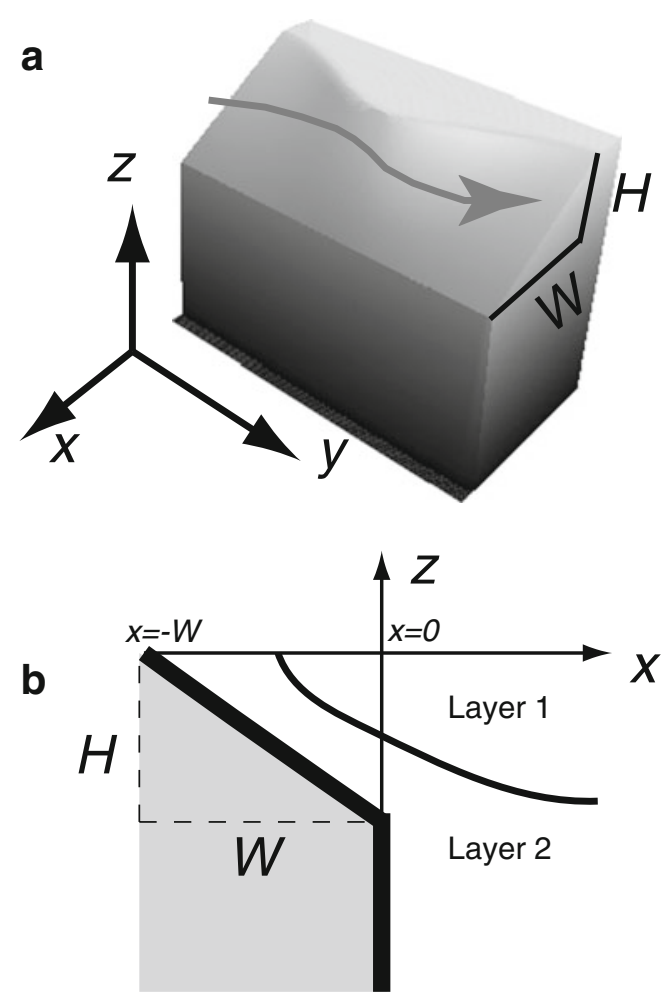

Fig. 15 a Schematic view of the coastal model. The continental shelf has a linear slope (function of $y$ ) of width $W$ and height $H$. b Crossshore vertical section of the model. The model has two layers on continental shelf, and 1.5 layers off the coast 
the curvature of the coastline is insignificant. From these assumptions, the alongshore component of the velocity is in geostrophic balance with the offshore pressure gradient. We also assumed that the potential vorticity within each layer is constant and equal to its value far offshore $f / D_{i}^{\infty}$, where $f$ is the Coriolis parameter and $D_{i}^{\infty}$ is the depth of each layer far offshore, and the velocities are negligible. This approach follows Stommel (1972), who used it as a good representation of the Gulf Stream. The lower layer is assumed to be of deep ocean origin with zero potential vorticity $\left(D_{2}^{\infty}=\infty\right)$.

From the above settings, the following equations are obtained:

$$
\left.\begin{array}{r}
f v_{i}=\frac{\partial p_{i}}{\partial x} \\
p_{1}-p_{2}=g^{\prime} D_{1} \\
\left(f+\frac{\partial v_{1}}{\partial x}\right) / D_{1}=f / D_{1}^{\infty} \\
f+\frac{\partial v_{2}}{\partial x}=0
\end{array}\right\},
$$

where $p_{i}$ denotes the pressure divided by the density of each layer, $g^{\prime}=\mathrm{g}\left(\rho_{2}-\rho_{1}\right) / \rho_{0}$ is the reduced gravity between layers 1 and $2, g$ is the gravitational acceleration, $\rho_{i}$ is the density of each layer, and $\rho_{0}$ is a representative density. The first equation in Eq. 1 is the momentum equation in the $x$ direction. The second equation is the hydrostatic balance. The third and fourth equations represent the conservation of the potential vorticity of layers 1 and 2, respectively.

The equations in Eq. 1 can be written in nondimensional forms using $D_{1}^{\infty}$ as the unit of depth, the internal Rossby radius deformation $\mathrm{L}=\sqrt{\mathrm{g}^{\prime} \mathrm{D}_{1}^{\infty}} / \mathrm{f}$ as the unit of the horizontal distance, $f^{-1}$ as the unit of time, and $\mathrm{L} f$ as the unit of velocity. The nondimensional forms of the equations are

$$
\left.\begin{array}{r}
v_{i}=\frac{\partial p_{i}}{\partial x} \\
p_{1}-p_{2}=D_{1} \\
\left(1+\frac{\partial v_{1}}{\partial x}\right) / D_{1}=1 \\
1+\frac{\partial v_{2}}{\partial x}=0
\end{array}\right\} .
$$

The same notations as for the dimensional variables are kept for simplicity.

The equations are functions of $x$ only. Therefore, given the transport and topography at each point $y$, solutions can be obtained. As is usual in hydraulic control theory, there are two (conjugate) solutions: a slow (subcritical) flow with a deep layer thickness and a rapid (supercritical) flow with a shallow layer thickness (Gill and Schumann 1979; Dale and Barth 2001). With sufficient transport, the flow will transit smoothly from the subcritical flow to the supercritical flow through the critical (control) point where the wave and flow speed are equal, without violating the conservation of volume transport and potential vorticity.

The upper-layer solution can be split into four cases based on the location where the interface between the two layers hits the surface or the topography (Fig. 16). For convenience, a parameter $\alpha$ is defined to represent the location of the section of layer and topography or surface:

$\alpha=\left\{\begin{array}{c}b+W \quad(\text { outcrop on surface }) \\ -b-W \quad(\text { hit the continental shelf bed }) \\ -W \Delta / H \quad(\text { hit vertical shelf edge })\end{array}\right.$

where $b$ is the value of $x$ where the interface hits the surface or the topography, and $\Delta$ is as the value of $D_{1}$ at the vertical boundary at $x=0$ (Case (d)). $\alpha$ is defined so that it becomes positive when the interface outcrops on the surface and negative when the interface hits the shelf bed or the vertical shelf edge. The equations in Eq. 2 can be solved analytically (refer to Gill and Schumann (1979) and Dale and Barth (2001)). Our final solutions can be found in Appendix 1 . Using some examples, Appendix 2 demonstrates how flow pattern can be obtained from the equations.

\subsection{Application to the Kuroshio}

We used the values of constants following Kawabe (1990): $f=$ $0.8 \times 10^{-4} \mathrm{~s}^{-1}, g^{\prime}=0.02 \mathrm{~ms}^{-2}$. To represent the surface trapped current, we used $D_{1}^{\infty}=200 \mathrm{~m}$. Thus, the internal wave (Kelvin wave) speed is $c=\sqrt{g^{\prime} D_{1}^{\infty}}=2 \mathrm{~m} / \mathrm{s}$.

Because the theory can be applied only where the coastal curvature is insignificant, we used the region just around Cape Shionomisaki between $135.6^{\circ} \mathrm{E}$ and $135.9^{\circ} \mathrm{E}$ (Fig. 17). Considering circle with radius $r=80 \times 10^{3} \mathrm{~m}$ (blue curve in Fig. 17), ratio between centrifugal force and Coriolis term $\left(v^{2} / r\right) /(f v)$ is relatively small: 0.16 when $v \sim 1 \mathrm{~m} / \mathrm{s}$ before acceleration and 0.32 even when $v \sim 2 \mathrm{~m} / \mathrm{s}$ after acceleration. (Because Fig. 4 shows more zonal flow than this blue curve, the effect of the centrifugal force could be smaller than this estimate). The shape of the continental shelf ( $W$ and $H$ ) was determined as follows. The depth at the shelf edge $(H)$ was defined by the depth along $33.35^{\circ} \mathrm{N}$ (thick solid line in Fig. 17a). The width of continental shelf $(W)$ is the distance between the $33.35^{\circ} \mathrm{N}$ line and coastline at the sea surface. These values were obtained from the topography used in the JCOPE2 dataset. The values were nondimensionlized when used in the solutions.

Figure 18a shows the nondimensional velocity of the control flow using this topography. Figure 19a shows shelf width $W$ (thick solid line) and shelf edge depth $H$ (thick dashed line) along longitude. The nondimensional critical transport is calculated from $W(0.49)$ and $H(5.1)$ at $137.9^{\circ} \mathrm{E}$, where the continental shelf is the narrowest and the shallowest. In this case, the critical transport is 0.52 . Figure $19 \mathrm{~b}$ and $\mathrm{c}$ show the first layer velocity $v_{1}$ and the layer-interface depth $-D_{1}$, respectively, at $137,137.9$, and $138.5^{\circ} \mathrm{E}$. The transport is controlled so that the velocity becomes critical $\left(v_{1}=1\right.$, nondimensionlized by the internal wave speed $c$ ) at the cape (blue curve of Fig. 19b). As the flow approaches the 
Fig. 16 Schematic diagrams of the model showing four different cases with different locations of the layer interface. Each figure (a-d) corresponds to Cases (a)-(d) in Appendix 1. a Interface outcrops at the surface offshore of the shelf edge. b Interface outcrops at the surface onshore of the shelf edge. $\mathbf{c}$ Interface hits the shelf bed. d Interface hits the vertical shelf edge
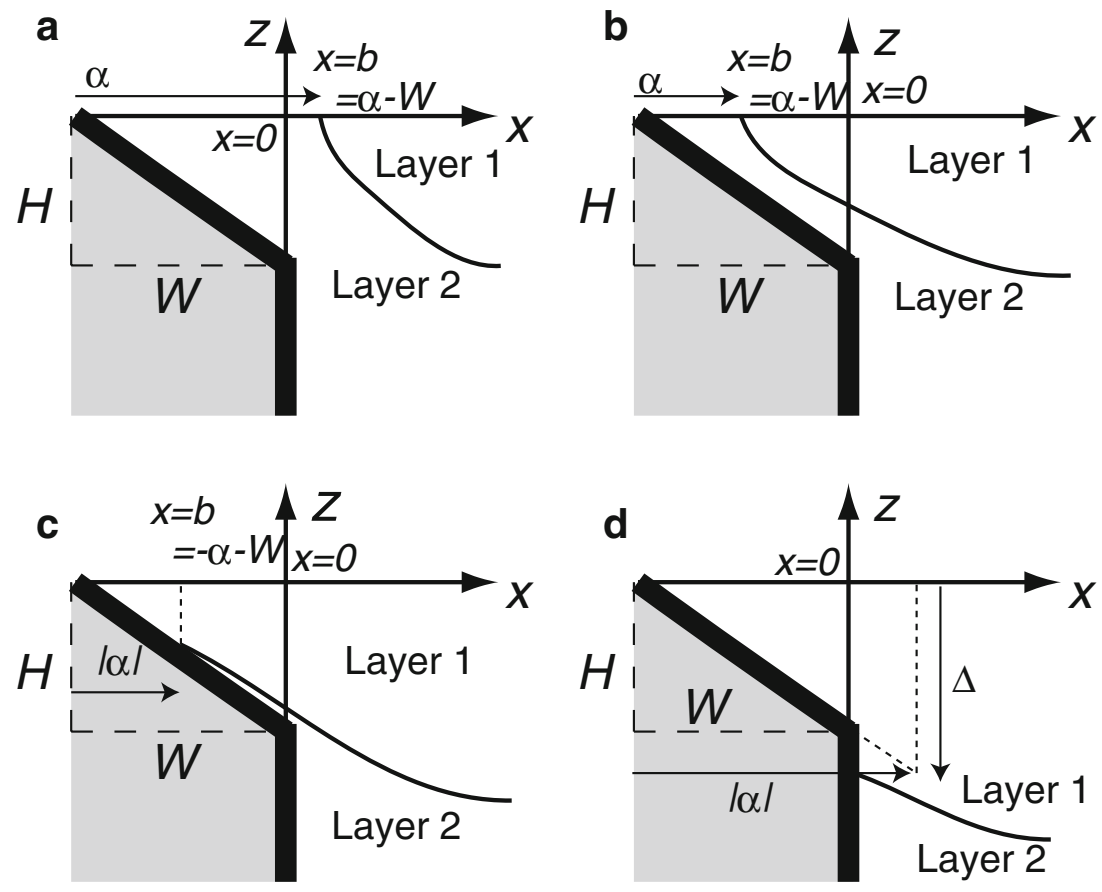

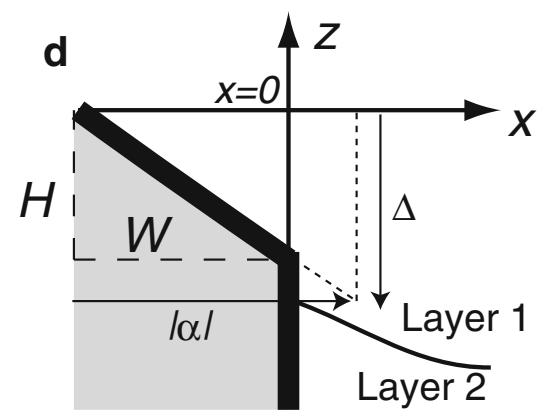

cape, the velocity of the first layer $v_{1}$ increases (Fig. 18a) because of the shallower and narrower topography (Fig. 19a). At the cape, the velocity finally becomes critical $v_{1}=1$ (blue curve of Fig. 19b). This allows a smooth transition to the downstream where the velocity is supercritical $v_{1}>1$ (the hatched region in Fig. 18a and red curve in Fig. 19b). As the velocity increases toward the cape, Layer 1 along the coast continues to become shallow (Fig 19c), and the layer interface moves toward the surface coastline. When the flow becomes supercritical, the interface outcrops at the surface (thick green line in Fig. 18a and red curve in Fig. 19c). Along the outcrop line, strong velocity shear is formed against the velocity of Layer $2 v_{2}$ (Fig. 18a).

As an example when the volume transport is less than the critical transport, Fig. 18b shows the velocity field when the volume transport is equal to factor 0.9 of that in Fig 18a. This represents the situation in which the Kuroshio path moves to the offshore and the volume transport near the coast decreases. In contrast to Fig. 18a, the velocity in Fig. $18 \mathrm{~b}$ is subcritical everywhere. The velocity increases as the flow approaches Cape Shionomisaki, but drops again as the topography becomes deep after passing Cape Shionomisaki. This solution is expected because any anomaly along the coast tends to be erased by the Kelvin wave propagation. Because the velocity is subcritical, such wave propagation is allowed. Therefore, except for the forced velocity increase around the shallow topography, the solution under the subcritical condition is rather uniform.

Conversely, when the velocity is strong enough to become critical as in Fig 18a, the wave propagation toward the upstream region that erases the non-uniformity is prevented.
Therefore, the supercritical flow on the downstream side is maintained.

The evidence that the Kuroshio in a near-shore path is under a critical condition is also suggested in Sugimatsu and Isobe (2010). They found that the areas where the internal Froude number is close to 1 are found near the Kii Peninsula when the Kuroshio axis lies close to the coast. They hypothesized that this situation prevents the cold water mass east of the peninsula from extending westward to the Kii Channel because the intense eastward Kuroshio flow "locks in" the cold water mass. Conversely, when the Kuroshio axis is away from the coast, the cold water east of the Kii Peninsula can be transported westward in the Kelvin wave.

To check sensitivity to selection of shelf-edge location, Fig. 20 shows the same results as Fig. 19, except for the case where the shelf edge is along the 1,500-m contour in Fig. 17. Therefore, nondimensional shelf edge depth is constant at 7.5. Although there are quantity differences (compare numbers in Figs. 19b and 20b), Fig. 20 also shows qualitatively similar results to Fig. 19. This is because the longitude of Cape Shionomisaki is still the narrowest shelf ( $W=0.62$ in this case), and therefore acts as the control point. The critical transport in this case is 0.53 . Selecting the shelf edge along the 1,000-m depth shows a similar result (not shown). Because our purpose is to show velocity acceleration is possible with linear-slope approximation of complicated topography, which is a more realistic representation of topography, Fig. 19 or Fig. 20, is out of our scope.

The hydraulic control solution in Fig. 18a captures some aspects of the Kuroshio acceleration reasonably well in the following ways: 

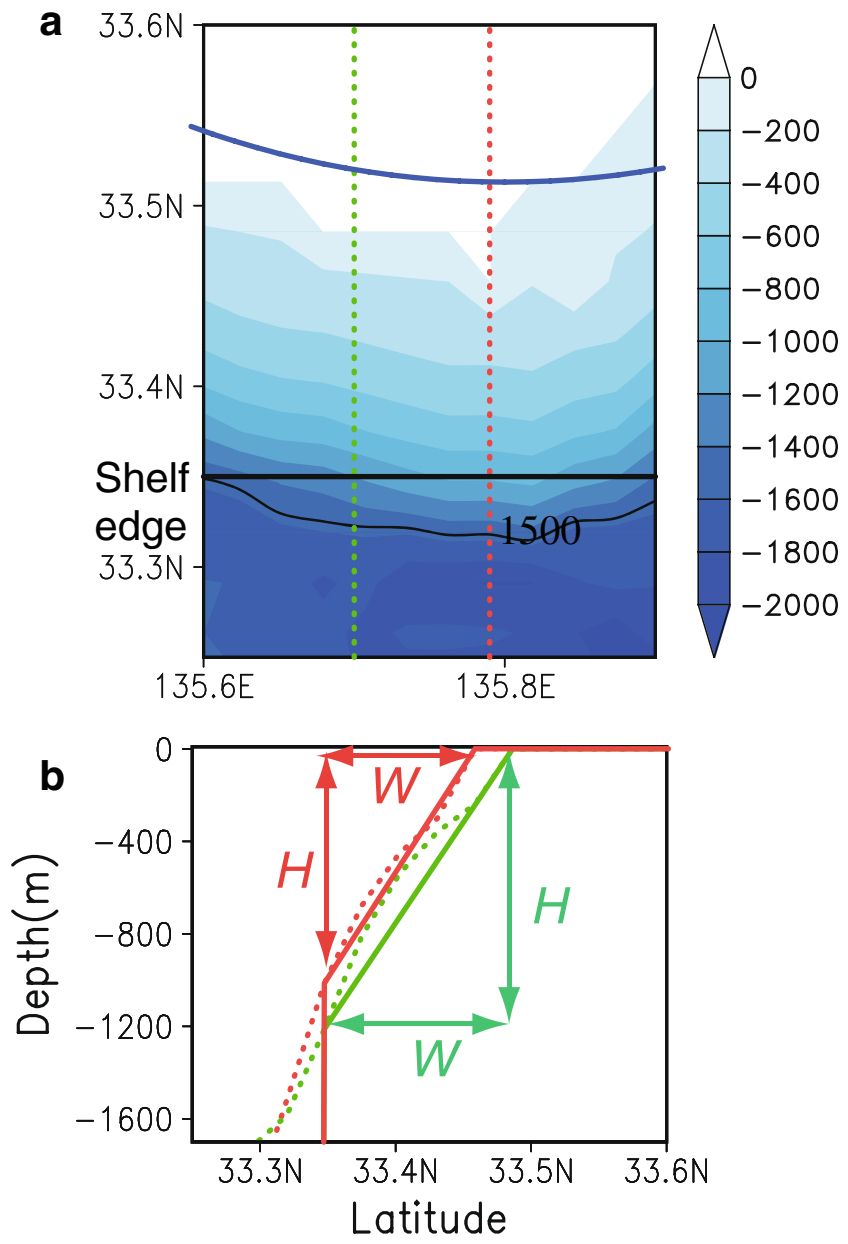

Fig. 17 Diagrams showing how the shape of the continental shelf is determined. a Horizontal map of the topography used in the JCOPE2 data (meters, blue shading). The $33.35^{\circ} \mathrm{N}$ line (thick solid line) is used for the shelf edge. Red (green) dotted line is along $135.8^{\circ} \mathrm{E}\left(135.7^{\circ} \mathrm{E}\right)$. White blank shows the model land. Blue curve is circle of radius $80 \mathrm{~km}$, which is used for scale analysis of centrifugal force in the text. b Topography at each longitudinal section. Dotted lines are the original topography. Solid lines are used for the analytical model. Red (green) lines correspond to the topography along $135.8^{\circ} \mathrm{E}\left(135.7^{\circ} \mathrm{E}\right)$. The depth at the shelf edge $(H)$ is defined by the depth along $33.35^{\circ} \mathrm{N}$. The width of the continental shelf $(W)$ is the distance between the $33.35^{\circ} \mathrm{N}$ line and the coastline at the sea surface

1. The solution explains why the Kuroshio acceleration occurs off Cape Shionomisaki. It is the shallowest and narrowest place on the continental shelf. In terms of the hydraulic control theory, it is the control point (Gill and Schumann 1979; Dale and Barth 2001). The velocity acceleration expresses the transition from a subcritical flow to a supercritical flow.

2. Beyond the cape, the outcrop of the interface occurs along the northern side of the accelerated velocity in the solution. This is consistent with the outcrop of cold temperature found in the JCOPE2 data on the downstream inshore side of Cape Shionomisaki.
3. The theory explains why the accelerated velocity is $\sim 2 \mathrm{~m} / \mathrm{s}$. It is comparable to the critical velocity speed against the internal wave speed $c$.

4. The theory explains the relation in Fig. 14 where the upstream flow should be strong enough to cause the Kuroshio acceleration. Sufficient velocity is needed for the transition from a subcritical flow to a supercritical flow.

5. Because the current theory uses the rigid-lid approximation, explaining the sea level difference directly is beyond the ability of this model. Sekine and Fujita (1999) showed that difference in vertically integrated specific volume mainly by temperature between off Kushimoto and off Uragami almost equals the difference in observed sea level between Kushimoto and Uragami. This suggests that the cold water outcropping accompanied by the flow separation explains sea level difference across the cape.

\section{Summary and discussion}

The sudden acceleration of the Kuroshio velocity off Cape Shionomisaki was captured in the high-resolution JCOPE2 ocean reanalysis data. The Kuroshio acceleration appears when the path of Kuroshio approaches the Japan coast. The velocity discontinuity is accompanied by cold water outcropping of the downstream inshore side of Cape Shionomisaki. This outcropping accompanied by the Kuroshio jet could be a favorable condition for upwelling, and thereby an area of primary production and fisheries. For example, Kuno et al. (2001) showed that good catching grounds of skipjack in the Kumano-Nada region often coincide with SST fronts along the northern edge of the Kuroshio and also correspond to chlorophyll- $a$ fronts.

A close relation between the bottom topography and jet acceleration suggests that the dynamics of the velocity jump is linked to the topographic features. Considering this relationship, we applied a hydraulic control theory to the Kuroshio acceleration. The analytical solution based on the hydraulic control theory satisfactorily captures some aspects of the Kuroshio acceleration.

How can the theoretical transport calculated by the hydraulic control be compared with the transport in the JCOPE2 reanalysis data? Theoretical critical transport for the cases of Figs. 19 and 20 are 0.52 and 0.53 , which correspond to dimensional value $Q_{1} L^{2} f H_{1}^{\infty}$ about $5 \mathrm{~Sv}$ ( $\mathrm{Sv}$ $\left.\equiv 10^{6} \mathrm{~m}^{3} \mathrm{~s}^{-1}\right)$. Unfortunately, it is not straightforward to compare this theoretical transport with the transport in the JCOPE2 data because the reanalysis data includes barotropic transport, eddies, and recirculation gyre, which are not included in the simple model. Figure 21 shows the time series of cumulative sum of the transport above $25 \sigma_{\theta}$ 
Fig. 18 Velocities of Layer 1 $\left(v_{1}\right)$ projected on the real map. The values are nondimensionlized by the internal wave speed $(c=2 \mathrm{~m} / \mathrm{s})$. a The critical case. The region where the velocity is supercritical $\left(v_{1}>1\right)$ is hatched. Layer 1 outcrops along the north of the supercritical region (thick solid green line). The velocity of Layer $2\left(v_{2}\right)$ to the north of the outcrop line is also plotted. b The subcritical case. In $\mathbf{a}$ and $\mathbf{b}$, values are nondimensional except that $x, y$ axes are projected on latitude, longitude axes. White blank shows the model land

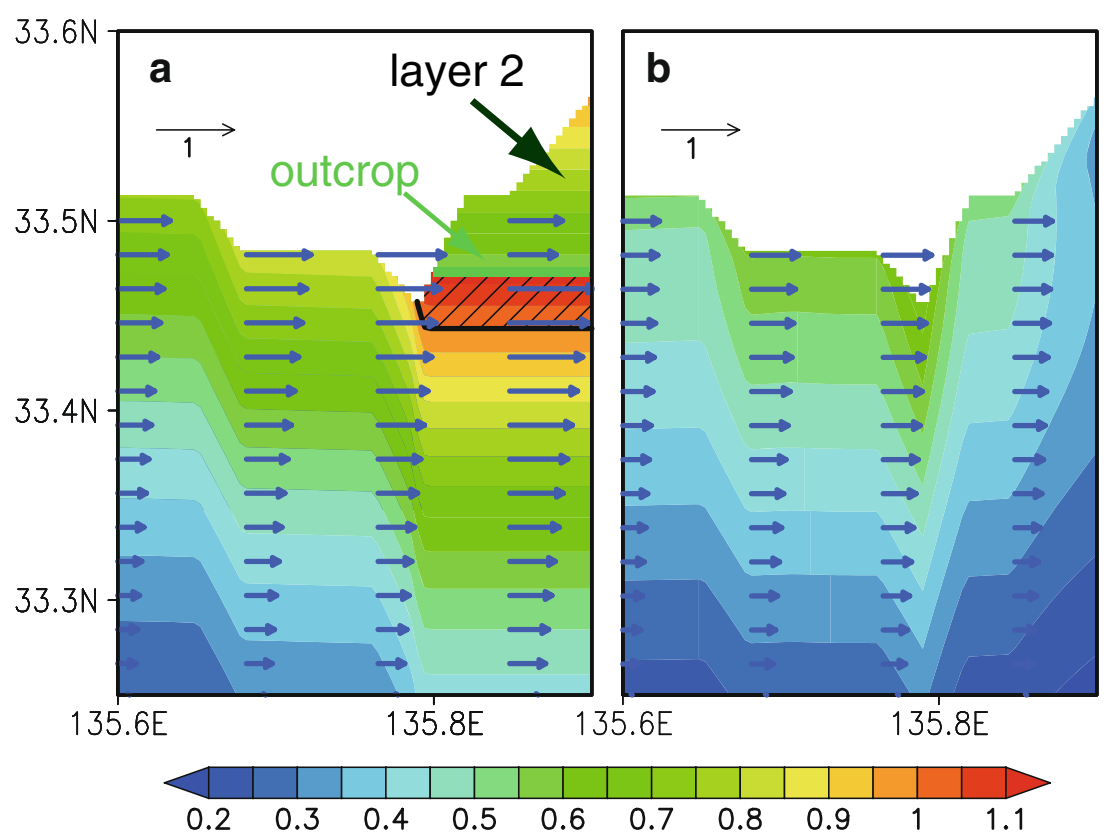

between the coast and each latitude along $135.7^{\circ} \mathrm{E}$. The value along $33^{\circ} \mathrm{N}$ means the transport between the coast and $33^{\circ} \mathrm{N}$. From 2003 to early 2004, the contour of $5 \mathrm{~Sv}$ (red thick line) in Fig. 21 is near the coast when the Kuroshio flows near the coast (Fig. 10). Therefore, Fig. 21 shows that the theoretically required transport is available near the coast when the flow acceleration actually occurs (Fig. 10). On the other hand, from late 2004 to early 2005, the contour of $5 \mathrm{~Sv}$ in Fig. 21 is away from the coast, and the value near the coast sometimes becomes negative when the Kuroshio flows away from the coast (Fig. 10). Therefore, required transport is not available near the coast. During such a period, the flow acceleration does not occur (Fig. 10). Thus, Fig. 21 is, at least qualitatively, consistent with our theory. For further quantitative discussion, more understanding of barotropic transport, eddies, and recirculation gyre is required. The decrease of transport from large value around $31^{\circ} \mathrm{N}$ to small value around $29^{\circ} \mathrm{N}$ indicates that negative (westward) transport exists. Such an order of recirculation, which makes the transport comparison difficult, is counted in the transport in Fig. 21.
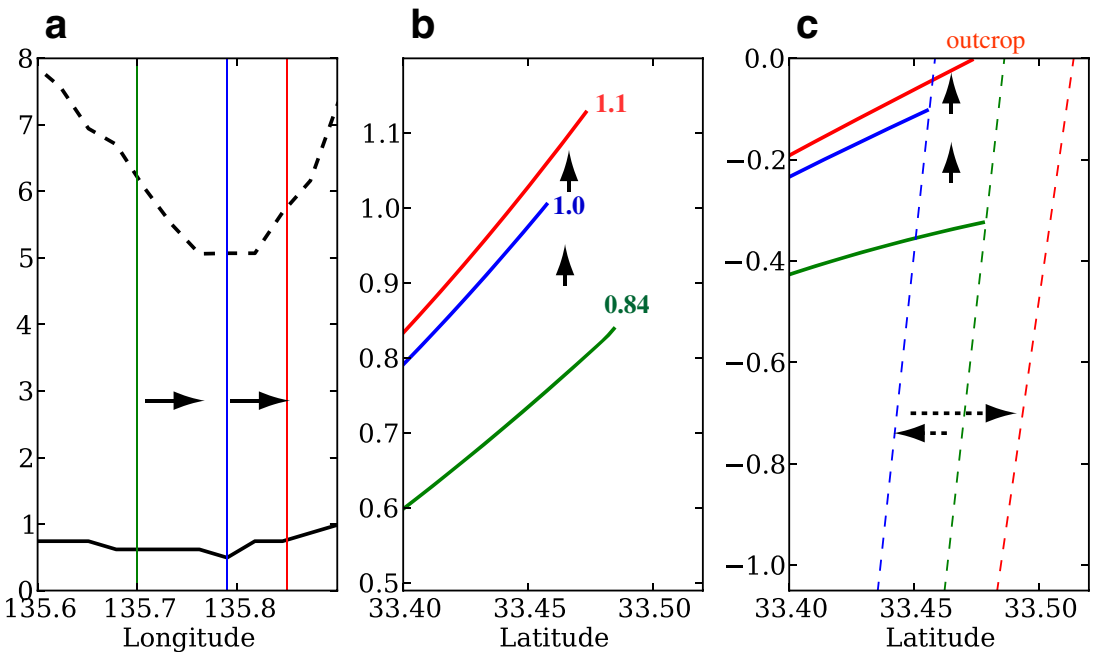

Fig. 19 a Shelf width $W$ (thick solid line) and shelf edge depth $H$ (thick dashed line) as the functions of longitude. b Thick solid line shows velocity of first layer $v_{1}$ of the critical solution (Fig. 18a) at each longitude as the function of latitude. Number is maximum value of each curve. c Solid line shows the depth of layer interface $-D_{1}$ of the critical solution (Fig. 18a) at each longitude as the function of latitude.
Dashed line is the linear slope of the model topography of each longitude. In a-d, values are non-dimensional except that $x, y$-axes are projected on latitude, longitude axes. Green, blue, and red colors represent values of $135.7,137.9$, and $138.5^{\circ} \mathrm{E}$, respectively. Arrows schematically show movements from upstream to downstream 
Fig. 20 Same as Fig. 19 except

for the case where

nondimensional shelf-edge

depth is constant at 7.5
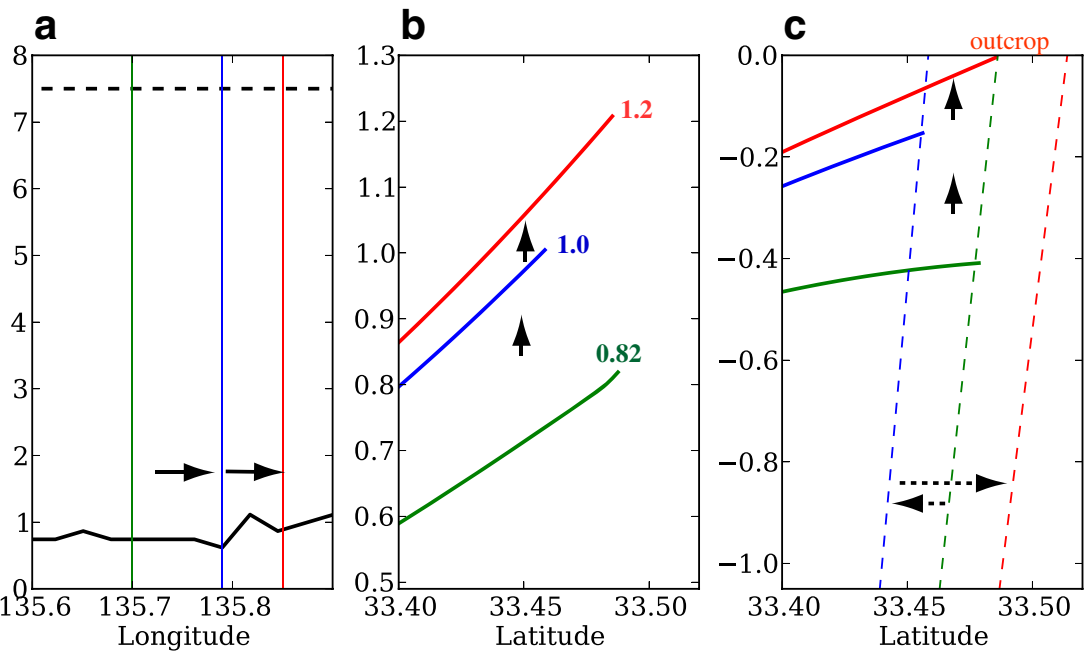

It must be noted that the analytical model used in this study is simplified. The assumptions used to derive the model solution must be carefully examined in further studies.

One of the factors in the analytical solution that was smoothed is curvature of the coastline. While Nagata et al. (1999) attributed the Kuroshio separation from the bottom slope to centrifugal forces by the coastal curvature near Cape Shionomisaki, our analytic solution shows that the coastline curvature is not necessary for the flow to leave the bottom slope. The flow leaves the bottom slope in the form of outcropping. The observation by Konaga et al. (1967) supports our conclusion in that the Kuroshio did not show significant curvature when the flow accelerated off Cape Shionomisaki.

Ou and De Ruijter (1986) developed the theory of coastal flow with a reduced gravity model without continental shelf. In their theory, flow variation along coast and flow separation from coast arise due to change of Coriolis parameter ( $\beta$-effect) and change of curvature (varying curvature, not like in Nagata et al. (1999), who considered a single curvature). Their theory concludes that the location of flow separation is highly dependent on the flow transport. However, the JCOPE2 results show that the location of the flow separation (and the velocity acceleration) is stable at Cape Shionomisaki. Therefore, we think that it is more reasonable to consider the effect of bottom topography as the anchor for the location. Appendix 2 shows the relation between $\mathrm{Ou}$ and De Ruijter (1986) and the hydraulic theory when $\beta$-effect and curvature are not included.

Nonetheless, the contribution of the actual topography of the coastline curvature is worth further investigation. Dale and Barth (2001) extended their hydraulic control solution to include a curvature. In their conclusion, the solution was essentially unchanged while the coastline convexity of the head of a cape slightly inhibited the transition to a supercritical downstream state by increasing the required critical transport. In other words, when the continental shelf is considered, coastline curvature makes downstream outcropping difficult, the opposite conclusion to that of Ou and De Ruijter (1986).
Because the purpose of the theory is the shelf-like topography near Cape Shionomisaki can generate the sudden velocity acceleration in the first order, how the Kuroshio approach the continental shelf and leave there is out of our scope. In the upstream side, an interesting topic is dynamics of the Kii Bifurcation Current (Furiwakeshio) shown in Fig. 4. Interestingly, Gill and Schumann (1979) showed bifurcation flow in the upstream side of cape-like topography in an example of their hydraulic control theory (their Fig. 5c). In the downstream side, coastline rapidly retreats toward the north. This can be seen in departure between the blue curve and the model coastline. Although this retreat would not significantly affect the first layer velocity because the first layer leaves the coastline in the downstream, the second layer might be different. Strong velocity near the coast in the second layer in Fig. 18a (such a strong velocity along the coast is not found in the JCOPE2 data) is because

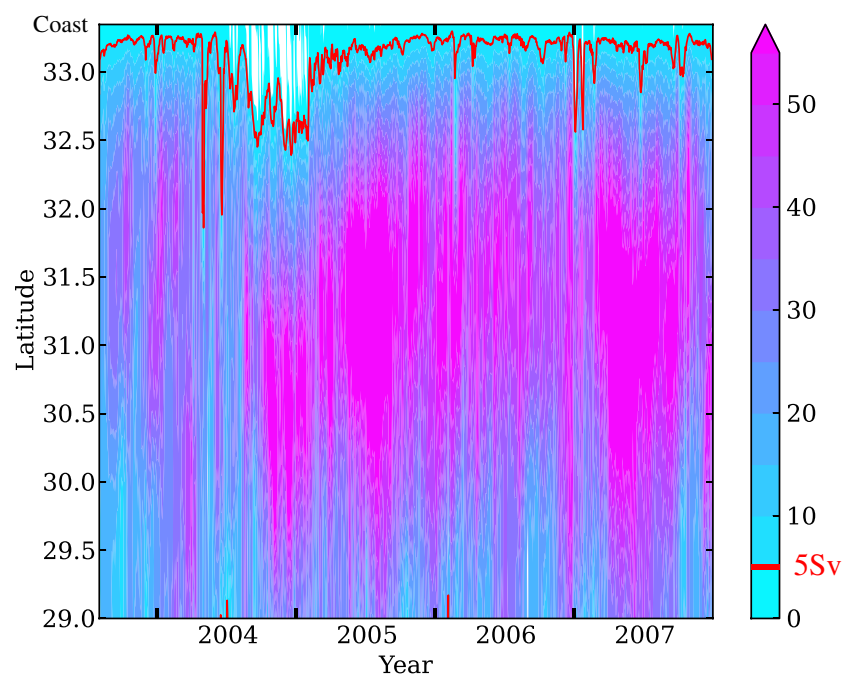

Fig. 21 Time series of cumulative sum of the transport above $25 \sigma_{\theta}$ between the coast and each latitude along $135.7^{\circ} \mathrm{E}$. Thick red line is the contour of $5 \mathrm{~Sv}$. White blank shows negative transport 
of the wide shelf: the second layer velocity $v_{2}$ has the relation $v_{2}=-x$. This calls for further improvement of the theory. Another interesting aspect of the rapid northward retreat of the coast is that it might allow more space for the eddy activities mentioned below. While we treated the JCOPE2 reanalysis data like observation, numerical modeling with higher resolution is another needed research investigating effect of small-scale topographic features because the coastline of the JCOPE2 data of the current resolution (Fig. 4) is simplified one from reality (Fig. 1).

The assumption of uniform potential vorticity is widely used to solve hydraulic control along the coast (Gill and Schumann 1979; Dale and Barth 2001; Mitsudera et al. 2011). The uniformity assumption permits an analytical solution by restricting the coastal waves to internal Kelvin waves. Allowing for the gradient of the potential vorticity in each layer is a challenging task of the hydraulic control theory for coastal applications. Hughes (1985) extended Gill and Schumann's (1979) theory by including the potential vorticity gradient in the first layer of the two-layer system. This system allowed multiple criticalities by the Kelvin-type wave and the shelf-type wave. However, it still needed the assumption of the zero potential vorticity of the second layer. The inclusion of barotropic transport explored by Mitsudera et al. (2011) and Pratt and Armi (1990) is another interesting direction to extend our theory because the layer model used in this paper only captures the baroclinic surface flow.

We believe that the time variation of the Kuroshio acceleration is one of the most interesting subjects for further investigations. Although the analytical solution in this study is steady, the flow around Cape Shionomisaki in reality fluctuates as shown in the black line of Fig. 10. The flow transport is not always likely to be the exact transport predicted by the steady hydraulic control theory. When the upstream transport increases, the hydraulic control theory holds that the flow self-adjusts by shedding waves, so that the criticality of the flow is restored (Dale and Barth 2001; Pratt and Whitehead 2007). If this control theory is applicable, there is a possibility that Cape Shionomisaki regulates the behavior of the Kuroshio flow on a large scale. In addition, the fluctuations around Cape Shionomisaki could be adjustment processes to the controlled state. Adjustments of the flow to a cape-like topography, Cape Shionomisaki in mind, have been explored by several studies (Yamagata and Umatani 1989; Mitsudera and Grimshaw 1994; Waseda et al. 2005). We are also currently investigating the variations of the Kuroshio from the view point of adjustments to the topography of Cape Shionomisaki.

Acknowledgments This work is a part of the Japan Coastal Ocean Predictability Experiment (JCOPE) promoted by the Japan Agency for Marine-Earth Science and Technology (JAMSTEC). We would like to thank Drs. Varlamov, Tsunoda, Mitsudera, Waseda, and Nishigaki for their helpful discussions.
Open Access This article is distributed under the terms of the Creative Commons Attribution License which permits any use, distribution, and reproduction in any medium, provided the original author(s) and the source are credited.

\section{Appendix 1: Analytic solutions}

The solutions of the linear equations are as follows. Each case (a-d) corresponds to cases in (a) to (d) in Fig. 16.

$D_{i}, p_{i}$, and $v_{i}$ are the thickness, pressure divided by density, and velocity of layer i. $p_{0}$ and $v_{0}$ are $p_{1}$ and $v_{1}$ where $D_{1}$ becomes zero.

For all cases:

The volume transport of the first layer is

$Q_{1}=1-p_{0}-\frac{1}{2} v_{0}^{2}$

The velocity in the second layer is always $v_{2}=0$ offshore $(x \geq 0)$. If $v_{2}$ exists on the continental slope (Cases a-c), $v_{2}$ is

$v_{2}=-x$

Case (a): the layer interface outcrops on the surface offshore of the shelf edge at $x=\alpha-\mathrm{W}>0$

$$
\begin{aligned}
& \text { At } 0 \leq-W+\alpha \leq x, \\
& \begin{array}{l}
D_{1}=-e^{\alpha-W-x}+1 \\
p_{1}=-e^{\alpha-W-x}+1 \\
v_{1}=e^{\alpha-W-x} \\
\text { At } x=\alpha-W, \\
p_{0}=0 \\
v_{0}=1
\end{array}
\end{aligned}
$$

Case (b): the layer interface outcrops on the surface onshore of the shelf edge at $x=\alpha-\mathrm{W} \leq 0$

$$
\begin{aligned}
& \text { At } 0 \leq x, \\
& \begin{array}{l}
D_{1}=-\frac{e^{-(\alpha-W)}+e^{\alpha-W}}{2 e^{\alpha-W}} e^{-x}+1 \\
p_{1}=-\frac{e^{-(\alpha-W)}+e^{\alpha-W}}{2 e^{\alpha-W}} e^{-x}+1 \\
v_{1}=\frac{e^{-(\alpha-W)}+e^{\alpha-W}}{2 e^{\alpha-W}} e^{-x} \\
\text { At }-W \leq-W+\alpha \leq x<0, \\
D_{1}=\frac{1}{2} e^{x}-\frac{1}{2} e^{2(\alpha-W)} e^{-x} \\
p_{1}=\frac{1}{2} e^{x}-\frac{1}{2} e^{2(\alpha-W)} e^{-x}-\frac{1}{2} x^{2} \\
v_{1}=\frac{1}{2} e^{x}+\frac{1}{2} e^{2(\alpha-W)} e^{-x}-x
\end{array}
\end{aligned}
$$




$$
\text { At } x=\alpha-W \text {, }
$$

$p_{0}=-\frac{1}{2}(\alpha-W)^{2}$

$v_{0}=e^{(\alpha-W)}-(\alpha-W)$

Case (c): the layer interface hits the bed onshore of the shelf edge $x=-\alpha-W \leq 0$

At $0<x$,

$D_{1}=(\Delta-1) e^{-x}+1$

$p_{1}=(\Delta-1) e^{-x}+1$

$v_{1}=(1-\Delta) e^{-x}$

where $\Delta=-\mathrm{s} \alpha \mathrm{e}^{-\alpha-\mathrm{W}}-\frac{1}{2} \mathrm{e}^{-2(\alpha+\mathrm{W})}+\frac{1}{2}$

At $-W<-\alpha-W \leq x<0$,

$D_{1}=\frac{1}{2} e^{x}+\left(\Delta-\frac{1}{2}\right) e^{-x}$

$p_{1}=\frac{1}{2} e^{x}+\left(\Delta-\frac{1}{2}\right) e^{-x}-\frac{1}{2} x^{2}$

$v_{1}=\frac{1}{2} e^{x}-\left(\Delta-\frac{1}{2}\right) e^{-x}-x$

where $\Delta=-\mathrm{s} \alpha \mathrm{e}^{-\alpha-\mathrm{W}}-\frac{1}{2} \mathrm{e}^{-2(\alpha+\mathrm{W})}+\frac{1}{2}$

$$
\text { At }-W \leq x<-\alpha-W<0 \text {, }
$$

$D_{1}=s(x+W)$

$$
p_{1}=\frac{1}{2} s\left(\frac{1}{3}\left((x+W)^{3}+\alpha^{3}\right)-\left(\alpha^{2}-2 \alpha\right)(x+\alpha+W)\right)
$$$$
-\frac{1}{2}\left(x^{2}-(\alpha+W)^{2}\right)+e^{-\alpha-W}(x+\alpha+W)-s \alpha
$$$$
-\frac{1}{2}(\alpha+W)^{2}
$$

$v_{1}=\left\{-\frac{1}{2} s \alpha^{2}+s \alpha+W+e^{-\alpha-W}\right\}-(x+W)$

$$
+\frac{1}{2} s(x+W)^{2}
$$

$$
\text { At } x=-W \text {, }
$$

$p_{0}=s\left(\alpha^{2}-\alpha-\frac{1}{3} \alpha^{3}\right)-\frac{1}{2} W^{2}+e^{-\alpha-W} \alpha$

Case (d): the layer interface hits the vertical shelf edge at $x=$ 0 and depth $\Delta=-\alpha H / W$

At $0 \leq x$,

$$
\begin{aligned}
& D_{1}=(\Delta-1) e^{-x}+1 \\
& p_{1}=(\Delta-1) e^{-x}+1 \\
& v_{1}=(1-\Delta) e^{-x}
\end{aligned}
$$

where $\Delta=-\alpha \mathrm{s}$

$$
\text { At }-W \leq x<0,
$$

$D_{1}=s(x+W)$

$p_{1}=\frac{1}{6} s x^{3}-\frac{1}{2}(-s W+1) x^{2}+(1-\Delta) x+\Delta$

$v_{1}=\frac{1}{2} s x^{2}+s W x-x+1-\Delta$

$$
\text { At } x=-W \text {, }
$$

$p_{0}=\frac{1}{3} s W^{3}-\frac{1}{2} W^{2}-(1-\Delta) W+\Delta$

$v_{0}=-\frac{1}{2} s W^{2}+W+1-\Delta$

\section{Appendix 2: Solutions for some examples}

To explain the characteristics of the analytical solutions in Appendix 1, we use the same example as Fig. 3 by Dale and Barth (2001). In this case, the shelf depth $H=1$ is constant. From upstream to downstream, the shelf width $W$ narrows from 4 to 2 toward a cape, and it widens again to 4 behind the cape. While Dale and Barth (2001) used the contoured transport for varying shelf width $W$ and the position of interface outcrop $\alpha$ in their Fig. 3, we plot the curve of volume transport $Q_{1}$ of Eq. 4 as the function of $\alpha$ for each $H$ (Fig. 22) to show the analytical solutions from another perspective using the same example.

The black curves in Fig. 22 for each $W$ (2 to 4$)$ is $1-p_{0}$ $-v_{0}^{2} / 2$ (Eq. 4) using the equations of Case (a)-(d) in Appendix 1. For example, $W=4$, Case (a) $\alpha>4$; Case (b) $0 \leq \alpha \leq 4$; Case (c) $-4 \leq \alpha<0$; and Case (d) $\alpha<-4$.

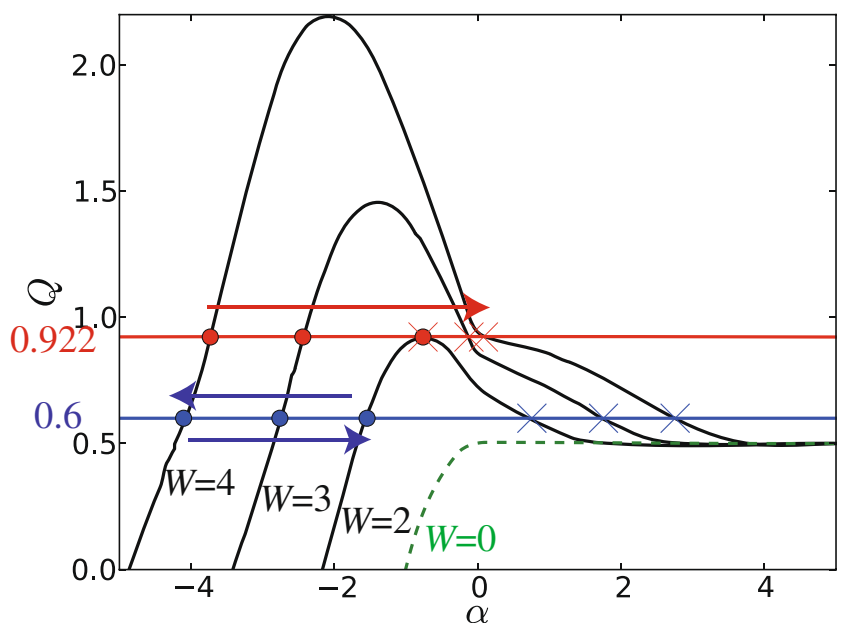

Fig. 22 Black curve is volume transports $Q_{1}$ of Eq. 4 as function of $\alpha$ for each $W(2,3$, and 4) when $H=1$. Blue (red) line corresponds to the volume transport $0.6(0.922)$. Closed circles (cross marks) represent subcritical (super-critical) solutions. Arrows schematically shows movements from upstream to downstream 
The blue curve represents the volume transport $Q_{1}=0.6$. From the relation of Eq. 4, the intersections of the blue line and the black curves decide $\alpha$. In other words, once the volume transport $Q_{1}$ is given, the shape of the current $(\alpha)$ is obtained depending on $W$ at each $y$. For $Q_{1}=0.6$, there are two (conjugate) solutions of $\alpha$ for each $W$ (marks of closed circle and cross). These two solutions are separated even for $W=2$, where two solutions are closest. As the flow moves on the shelf of $W$ from 4 to 2 and then $4, \alpha$ takes values on the closed marks (subcritical solutions) along the constant $Q_{1}=$ 0.6. Smooth transition to the positions of cross marks (supercritical solutions) is not allowed.

On the other hand, when the volume transport $Q_{1}=0.922$, two conjugate solutions are identical (a critical solution) when $W=2$. Therefore, the subcritical solutions can smoothly transit to the supercritical solutions at the cape $(W=2)$. The critical transport $Q_{1}=0.922$ can be obtained from the maximal value of the curve for $W=2$, where the shelf is narrowest.

When volume transport is greater than 0.922 , there is no solution for $W=2$. In other words, the solutions in Appendix 1 fail. See more discussions by Dale and Barth (2001) for such a case. When the volume transport is less than 0.5 , there are only subcritical solutions.

In Fig. 22, we also plot the curve of $Q_{1}$ (green dashed line) when $W \rightarrow 0$ while keeping $s=H / W=1$. This represents the situation where there is no continental shelf. The possible cases are the Case (a) $\alpha>0$, where the layer interface outcrop, and Case (d) $\alpha<0$, where the layer interface hits the vertical coastal wall (no shelf in this case). For $\alpha<0,-\alpha$ represents the depth $(\Delta=-\alpha)$ where the layer interface hits the vertical wall since $s=1$ (see Fig. 16d). $Q_{1}$ of Eq. 4 becomes

$$
Q_{1}= \begin{cases}0.5 & (\alpha \geq 0) \\ 0.5\left(1-\alpha^{2}\right) & (\alpha<0)\end{cases}
$$

When the current flow along the coast $(\alpha<0)$, the green curve shows that the volume transport $Q_{1}$ must be less than 0.5 , and there is only a subcritical solution. This solution is essentially the same as of Ou and Ruijter (1986) when there is no curvature of coastline (see their Section 3, and their Eq. 3.1 is equivalent to our Eq. 18). Because there is only one curve of $Q_{1}$ (no dependency on $H$ or $W$ ), there is only one value of $\alpha$ once $Q_{1}$ is given. In other words, there is no change from upstream to downstream in the system of the current assumptions. In Ou and Ruijter (1986), change of Coriolis parameter ( $\beta$-effect) and change of curvature (varying curvature) along the coast is necessary for alongshore change of flow. When $Q_{1} \geq 0.5$, the interface outcrop, and there is no interaction between the flow and the coastline (Ou and Ruijter 1986). Note that there is no second layer flow because there is no continental shelf.

\section{References}

Dale AC, Barth JA (2001) The hydraulics of an evolving upwelling jet flowing around a cape. J Phys Oceanogr 31(1):226-243. doi:10.1175/1520-0485(2001)031<0226:THOAEU>2.0.CO;2

Gill AE, Schumann EH (1979) Topographically induced changes in the structure of an inertial coastal Jet - application to the Agulhas Current. J Phys Oceanogr 9(5):975-991. doi:10.1175/1520-0485 (1979)009<0975:TICITS $>2.0$. CO;2

Guo XY, Hukuda H, Miyazawa Y, Yamagata T (2003) A triply nested ocean model for simulating the Kuroshio-roles of horizontal resolution on JEBAR. J Phys Oceanogr 33(1):146-169. doi:10.1175/ 1520-0485(2003)033<0146:ATNOMF>2.0.CO;2

Hughes RL (1985) Multiple criticalities in coastal flows. Dyn Atmos Oceans 9(4):321-340. doi:10.1016/0377-0265(85)90007-7

Hukuda H, Guo X, Yamagata T (2002) A numerical model study of "Furiwakeshio" (in Japanese). Umi no Kenkyu 11(5):513-527

Kagimoto T, Miyazawa Y, Guo X, Kawajiri H (2008) High resolution Kuroshio forecast system-description and its applications. In: Ohfuchi W, Hamilton K (eds) High resolution numerical modeling of the atmosphere and ocean. Springer, New York, pp 209-234

Kawabe M (1989) Sea level changes south of Japan associated with the non-large-meander path of the Kuroshio. J Oceanogr Soc Japan 45(3):181-189. doi:10.1007/BF02123462

Kawabe M (1990) A steady model of typical non-large-meander paths of the Kuroshio current. J Oceanogr Soc Japan 46(2):55-67. doi:10.1007/BF02124815

Konaga S, Shuto K, Kusano H, Hori K (1967) On the relation between Kuroshio strong currents and the water temperature of $200 \mathrm{~m}$ depth (II) (in Japanese). Umi to Sora 43(2):10-15

Konaga S, Shuto K, Kusano H, Hori K (1971) On the relation between Kuroshio strong currents and the water temperature of $200 \mathrm{~m}$ depth (III) (in Japanese). Umi to Sora 46(3,4):77-85

Kuno M, Yamakawa T, Ito K, Matsumura S (2001) Skipjack fishing ground analysis by means of satellite remote sensing. In: Proceeding of the Korea-Japan Joint GLOBEC Symposium on long-term variations in the northwestern Pacific ecosystem. pp 217-223. http://dc160.4shared.com/img/x1DeO n4/preview.html

Minami H (1977) Sudden increase of the Kuroshio surface current off Shionomisaki and the role of the southward flow off KumanoNada (in Japanese). Umi to Sora 53(1):15-22

Mitsudera H, Grimshaw R (1994) Capture and resonant forcing of solitary waves by the interaction of a baroclinic current with topography. J Phys Oceanogr 24(11):2217-2244. doi:10.1175/ 1520-0485(1994)024<2217:CARFOS >2.0.CO;2

Mitsudera H, Uchimoto K, Nakamura T (2011) Rotating stratified barotropic flow over topography: mechanisms of the cold belt formation off the Soya Warm Current along the northeastern coast of Hokkaido. J Phys Oceanogr 41(11):2120-2136. doi:10.1175/2011jpo4598.1

Miyazawa Y, Kagimoto T, Guo X, Sakuma H (2008) The Kuroshio large meander formation in 2004 analyzed by an eddy-resolving ocean forecast system. J Geophys Res 113:C10015. doi:10.1029/ 2007JC004226

Miyazawa Y, Zhang RC, Guo XY, Tamura H, Ambe D, Lee JS, Okuno A, Yoshinari H, Setou T, Komatsu K (2009) Water mass variability in the Western North Pacific detected in a 15-year eddy resolving ocean reanalysis. J Oceanogr 65(6):737-756. doi:10.1007/s10872009-0063-3

Nagata Y, Takeuchi J, Uchida M, Ishikura I, Morikawa Y, Koike T (1999) Current nature of the Kuroshio in the vicinity of the Kii Peninsula. J Oceanogr 55(3):407-416. doi:10.1023/ A:1007858516891

Oey LY, Chen P (1992) A nested-grid ocean model-with application to the simulation of meanders and eddies in the 
Norwegian Coastal Current. J Geophys Res 97(C12):2006320086. doi:10.1029/92JC01991

Ou HW, De Ruijter WPM (1986) Separation of an internal boundary current from a curved coastline. J Phys Oceanogr 16(2):280-289

Pratt L, Armi L (1990) Two-layer rotating hydraulics: Strangulation, remote and virtual controls. Pure Appl Geophys 133(4):587-617. doi:10.1007/BF00876224

Pratt LJ, Whitehead JA (2007) Rotating hydraulics: nonlinear topographic effects in the ocean and atmosphere. Springer, New York

Sekine Y, Fujita K (1999) Why does the sea level difference between Kushimoto and Uragami show periods of large meander and nonlarge meander paths of the Kuroshio south of Japan? J Oceanogr 55(1):43-51. doi:10.1023/A:1007857005988

Shuto K (1979) The flow conditions of the Kuroshio in the vicinity of Cape Shionomisaki. Oceanogr Mag 30:1-14

Stommel H (1972) The Gulf Stream: a physical and dynamical description. University of California Press, California

Sugimatsu K, Isobe A (2010) Intrusion of Kuroshio-derived bottom cold water into Osaka Bay and its possible cause. J Oceanogr 66:191-199. doi:10.1007/s10872-010-0017-9
Takeuchi J, Honda N, Morikawa Y, Koike T, Nagata Y (1998) Bifurcation current along the southwest coast of the Kii Peninsula. J Oceanogr 54(1):45-52. doi:10.1007/BF02744380

Uchida M, Takeuchi J, Morikawa Y, Maekawa Y, Momose O, Koike T, Nagata Y (2000) On structure and temporal variation of the bifurcation current off the Kii Peninsula. J Oceanogr 56(1):1730. doi:10.1023/A:1011106306719

Usui N, Tsujino H, Fujii Y, Kamachi M (2008a) Generation of a trigger meander for the 2004 Kuroshio large meander. J Geophys Res 113 (C1):doi:10.1029/2007jc004266

Usui N, Tsujino H, Nakano H, Fujii Y (2008b) Formation process of the Kuroshio large meander in 2004. J Geophys Res 113(C8): doi: $10.1029 / 2007 \mathrm{jc} 004675$

Waseda T, Mitsudera H, Taguchi B, Kutsuwada K (2005) Significance of high-frequency wind forcing in modelling the Kuroshio. J Oceanogr 61(3):539-548. doi:10.1007/s10872-005-0061-z

Yamagata T, Umatani S (1989) Geometry-forced coherent structures as a model of the Kuroshio large meander. J Phys Oceanogr 19(1):130-138. doi:10.1175/1520-0485(1989)019<0130: GFCSAA $>2.0 . \mathrm{CO} ; 2$ 